\title{
Crushing and energy absorption performance of different geometrical shapes of small- scale glass/polyester composite tubes under quasi-static loading conditions
}

\author{
Sivakumar Palanivelu ${ }^{1}$, Wim Van Paepegem ${ }^{1}$, Joris Degrieck ${ }^{1}$, John Vantomme ${ }^{2}$, Dimitrios \\ Kakogiannis $^{3}$, Johan Van Ackeren ${ }^{3}$, Danny Van Hemelrijck ${ }^{3}$, Jan Wastiels ${ }^{3}$ \\ ${ }^{1}$ Department of Materials Science and Engineering, Ghent University, Sint-Pietersnieuwstraat 41, 9000 Gent, \\ Belgium \\ ${ }^{2}$ Royal Military Academy, Civil and Materials Engineering Department, Building G, Level 0, 8 Av. Hobbema \\ B-1000, Brussels, Belgium \\ ${ }^{3}$ Department of Mechanics of Materials and Constructions, Vrije Universiteit Brussel, Pleinlaan 2 B-1050 \\ Brussels, Belgium
}

\begin{abstract}
This paper presents the quasi-static crushing performance of nine different geometrical shapes of small-scale composite tubes. The idea is to understand the effect of geometry, dimension and triggering mechanism on the progressive deformation of small-scale composite tubes. Different geometrical shapes of the composite tubes have been manufactured by hand lay-up technique using uni-directional E-glass fabric (with single and double plies) and polyester resin. Dedicated quasi-static tests (144 tests) have been conducted for all nine geometrical shapes with different t/D (thickness to diameter) ratios and two triggering profiles ( $45^{\circ}$ chamfering and tulip pattern with an included angle of $90^{\circ}$ ). From this unique study, it was found that the crushing characteristics and the corresponding energy absorption of the special geometrical shapes are better than the standard geometrical shapes such as square and hexagonal cross sections. Furthermore, the tulip triggering attributed to a lower peak crush load followed by a steady mean crush load compared to the $45^{\circ}$ chamfering triggering profile which resulted into a higher energy absorption in most of the geometrical shapes of the composite tubes.
\end{abstract}

KEYWORDS: Composite tubes; Geometrical shapes; Triggering mechanism; Peak crush load; Progressive crushing; Specific energy absorption

\section{Introduction}

Protecting the civilian population against blast attacks is a complex and comprehensive task. If critical civil structures (tower buildings, embassies etc.,) are threatened, the main concerns are with the elaboration of an efficient rescue plan and a rapid intervention. The structural integrity of the engineering structure itself is rarely considered. However, since the early nineties (bomb attacks World Trade Centre (1993), Oklahoma (1995), US embassy Kenya (1998),World Trade Centre (2001)) the protection of civil engineering structures against explosions has become an important research area. Efforts have been made around the globe to propose suitable solutions for this problem. Out of many proposed solutions, the concept of sacrificial cladding design [1-3] has attracted more attention in terms of its functionality and its predictable behaviour. Any sacrificial cladding structure can have two layers (an outer skin and an inner core). The function of the outer skin is to distribute the blast pressure more evenly to the inner core which deforms progressively so that the peak force transferred to the non-sacrificial structure can be minimized. Structures using metals have been tried out for the inner core of the sacrificial cladding structure [1-3]. However, the cost related to material, manufacturing and its maintenance for metals and its alloys is higher $[4,5]$. Furthermore, use of these materials may lead to a heavy sacrificial structure. On the other hand, composite materials have relative advantages in terms of specific energy absorption, weight and maintenance [6, 7]. Hence, in this research composite tubes have been chosen for the inner core of the sacrificial cladding structure (refer Figure 1). Before designing the inner core of a full-scale sacrificial cladding the knowledge of the crushing performance of an individual composite tube is very important. During the crushing process the inner core composite tube has to exhibit (i) uniform and progressive crushing and (ii) a

*Corresponding author: Sivakumar Palanivelu, Tel: +32-(0)9-264.33.15, Fax: +32-(0)9-264.35.87 
high value of energy absorption. Therefore, a major question arises about the geometry, dimensions of the composite tube and its variables which can provide the above requirements. Hence, in this study the quasi-static testing was chosen to understand the above factors for different geometrical shapes of the composite tubes. The advantage of this approach is to eliminate few geometrical shapes of the composite tubes which show catastrophic or non-uniform failure; furthermore, due to the very slow speed of the crushing process the deformation mechanisms of the tubes can be easily captured. However, in order to study the effect of strain rate on the deformation mechanisms and the corresponding deformation patterns, the selected geometry (of the composite tubes) from this program have to be further studied for high dynamic tests such as impact and blast loading conditions.

Few studies $[7,8]$ indicated the list of parameters which alters the crushing performance of the composite tubes. The progressive crushing process which yields a higher energy absorption depends on the mechanical properties of the fibre and the resin, fibre and resin volume fractions, laminate stacking sequence, fibre orientation and the geometry of the tube $[7,8]$. However, for the same parameters, different levels of the specific energy absorption can be achieved by changing only the geometry of composite structures [9]. The effect of changing the dimensions on the energy absorption was studied in $[10,11]$ for the circular and square composite tubes. The general conclusion of these studies is that the $\mathrm{D} / \mathrm{t}$ ratio significantly affects the energy absorption capability of these composite tubes. Thornton [12] and Thornton et al. [13] demonstrated that the circular cross sectional composite tubes are more effective than the square and rectangular cross sectional composite tubes. Similar results were reported by Mamalis and his co-workers in [14, 15]. Jimenez et al. [16] conducted a study on open section such as "I" sectional tubes. The result of this research showed that the energy absorption capability of the "I" section profile is $15 \%$ smaller than the square cross sectional composite tube. Studies by Mamalis et al. [15, 17] on conical shells showed that the specific energy absorption decreases as the semi-apical angle of the frusta increases. Many of the published data [8, 9, 17-21] on the energy absorption of composite tubes utilized the circular and square cross sections. Furthermore, they all agreed that the geometrical shape is an important parameter which affects the energy absorption significantly.

Hull [9] stated that the shape and the dimensions of the composite structure are one of the five important variables affecting the specific energy absorption. Very few studies have been carried out on special shapes of the composite structures which are intended for specific applications. Mamalis et al. [22] investigated the energy absorption characteristics of a special shaped (horizontal hourglass) automotive rail frame made of glass/vinylester composite. They reported that the specific energy of the progressively collapsed rail beams is almost constant as the ratio $\mathrm{t} / \mathrm{L}$ (thickness/length) of the shell increases. Farley and Jones $[15,23]$ investigated the effect of reducing the included angle in carbon/epoxy elliptical composite tubes. They found that the specific energy absorption increases with decreasing the included angle. The specific energy absorption improved about $10 \%$ to $30 \%$ corresponding to the reduction of the included angle from $180^{\circ}$ to $90^{\circ}$. Elgalai et al. [24] investigated the crushing response of carbon/epoxy and glass/epoxy composite tubes in quasi static axial loading. They reported that the introduction of corrugation significantly enhanced the energy absorption capability of composite tubes. Zarei et al. [25] studied the energy absorption characteristics of a hexagonal box with vertical ribs. These test specimens were manufactured from woven fiberglass/polyamide plates using thermoforming welding method. Abdewi et al. [26] studied the quasi-static axial and lateral crushing of radial corrugated glass/epoxy

*Corresponding author: Sivakumar Palanivelu, Tel: +32-(0)9-264.33.15, Fax: +32-(0)9-264.35.87 
composite tubes. They concluded that the radial corrugation significantly influenced the energy absorption of the composite tubes.

As we noticed in the previous paragraphs different forms of energy absorbing composite structures are studied for specific applications. However, the dimensions of these composite test specimens are generally larger than the inner core structures of the proposed sacrificial cladding structure (Figure 1). Furthermore, there are several shapes of composite tubes whose energy absorption capabilities have not been studied yet. Few examples of such geometrical shapes (Hourglass type - A, Hourglass type - B, Hourglass type - X, Hourglass type- Y and Conical circular type - X) are shown in Figure 2. Hence, in order to study the influence of geometry on the energy absorption, nine different geometrical shapes have been chosen (Figure 2). Due to a higher performance to cost ratio and the acceptance in many applications the E-glass fabric and the polyester resin were chosen. Few studies [18, 27] demonstrated that the fibre orientation along the axis of the tube absorbed more energy than other orientations. In connection with the above factors the uni-directional fibre configuration was chosen for our study. The effect of scaling (based on t/D ratio and the size) on the performance of composite structures have been studied in refs [28, 29]. The general conclusion of these researches is the crush zone fracture mechanisms were influenced by the tube or the structure dimensions and these fracture mechanisms determine the overall energy absorption capability of composite tubes. In order to scale these composite tubes for different energy absorption values and to study the influence of $t / D$ ratio, two different $t / D$ ratios have been considered for the study. To produce a significant deceleration during the crush event, the failed tubes should exhibit delamination, bending, axial cracking and fibre fracturing modes [8]. To achieve the above said failure modes and to reduce the peak crush load, an initiator for the stable progressive crushing is very important. Normally these initiators are known as "triggering" mechanisms. Many researchers [7, 10, 11, 17, 30, 31] employed the edge chamfering of the structures as triggering mechanism. Few studies have been conducted with square tubes and "I" sectional tubes to study the effect of triggering on the energy absorption $[16,21]$. However, the effect of triggering mechanisms on the energy absorption of other geometrical shapes is yet to be captured. Hence, it is worth to investigate the role of different triggering mechanisms on the energy absorption of uniform and non-uniform geometrical shapes. To study the effect of triggering on the crushing behaviour and the corresponding energy absorption two different triggering mechanisms ( $45^{\circ}$ chamfering around the edge and tulip triggering with an included angle between the edges is $90^{\circ}$ (refer Figure 4) were chosen. In order to understand the crushing behaviour and the corresponding energy absorption of these small-scale composite tubes the quasi-static axial crushing tests were conducted. The test parameters such as the specific energy absorption, peak crush load, mean crush load and the efficiency of the crushing process are presented. All the composite tube specimens have been manufactured by hand lay-up using E-glass fabric, polyester resin and polyurethane foam mandrels, as explained in subsequent section.

\section{Materials and manufacturing of composite tubes}

\subsection{Materials and dimensional details of the composite tubes}

The composite tubes tested in this investigation were fabricated by hand lay-up using a uni-directional E-glass fabric (Roviglass R475/17). In the fibre direction $\overrightarrow{\mathrm{e}}_{11}$, the reinforcement was $475 \mathrm{~g} / \mathrm{m}^{2}$, while in the direction $\vec{e}_{22}$, the reinforcement was $17 \mathrm{~g} / \mathrm{m}^{2}$ (refer Figure 3(a) and 4. The Synolite 1408-P-1 polyester resin (low viscous, pre-accelerated, promoted thixotropic medium reactive unsaturated polyester resin) was used to manufacture

*Corresponding author: Sivakumar Palanivelu, Tel: +32-(0)9-264.33.15, Fax: +32-(0)9-264.35.87

Email: Sivakumar.Palanivelu@UGent.be 
the composite tubes. Studies conducted on the progressive crushing of circular cross sectional composite tubes proved that tubes having a t/D ratio less than 0.015 will fail catastrophically [28]. However, tubes with a t/D ratio in the range of 0.015 to 0.25 will crush progressively. Hence, the $t / D$ and $t / W$ (thickness to width) ratio of the tubes were chosen as per the above recommendation for $1 \mathrm{~mm}$ and $2 \mathrm{~mm}$ thickness tubes (refer Table 1). The average diameter was considered for $\mathrm{t} / \mathrm{D}$ calculation for the composite tubes with non-uniform cross section along their length and the calculated average values (from 4 test specimens) for each composite tube series are given in Table 1. The length of all the composite tubes was restricted to $100 \mathrm{~mm}$. A polyurethane foam with density of $104 \mathrm{~kg} / \mathrm{m}^{3}$ was used to make all the mandrels (refer Figure 3 (b)).

\subsection{Fabrication}

Due to the versatile advantages such as low tooling cost, start-up and low capital cost the hand lay-up technique was chosen to manufacture all composite tubes. The steps involved in the fabrication of the composite tubes are as follows: (i) initially, the polyurethane foam mandrels were made as per the inner dimensions of the composite tubes. The fabricated polyurethane foam mandrels for a few geometrical shapes were shown in Figure 3(b). (ii) secondly, the E-glass fibre mat was cut into the developed length for each geometrical shape of the composite tubes. (iii) in the third stage, these polyurethane foam mandrels were mounted on a rotating rod which was clamped at both ends (the filament winding machine was used for this purpose). The Synolite 1408-P-1 polyester resin was uniformly applied on the surface of the rotating polyurethane foam mandrel. Subsequently, the E-glass fibre mat was placed and wrapped around the polyurethane foam mandrel; and further, the polyester resin was applied on that. Special care was taken not to alter the fibre orientations during the wrapping and resin application process. The polyester resin was cured with $1 \%$ Butanox M50 before applying on the mandrel and the E-glass fabric. Finally, the composite tubes were post-cured for 24 hours at room temperature followed by 24 hours at $60^{\circ} \mathrm{C}$ and 24 hours at $80^{\circ} \mathrm{C}$ as per the supplier recommendation. After curing, the polyurethane foam inside the composite tube was removed by using special tools. The used number of E-glass fabric layers to achieve $1 \mathrm{~mm}$ and $2 \mathrm{~mm}$ thicknesses of the composite tubes was one and two respectively. Later the triggering geometry was introduced on one side of the composite tubes and the details of the triggering (type 1 and type 2) are shown in Figure 4(a) and 4(b). The motivation to choose these types was: for type 1 profile the initial contact of the crushing platform will be uniform along the circumference of the tube, whereas in the case of type 2 the contact will take place at the sharp edges of the specimen. The first mechanism would enhance uniform circumferential interlaminar cracks causing uniform delamination, whereas, in the case of triggering type 2, the initial cracks develop at the sharp edges of the tube which make first contact with the crushing platform. Totally, 36 composite tube series were tried out to study the deformation patterns and their corresponding energy absorption behaviour. The nomenclature and the corresponding dimensional details of the composite tube series are given in Table 1. The average linear density (mass per unit length) measured from four tubes for each composite tube series is reported in Table 1. The finished samples of a few composite tube series are shown in Figure 5.

\section{Experimental results and discussions}

The deformation patterns and the corresponding load-deformation histories of all the composite tubes were studied for quasi-static axial compressive loading condition. An

*Corresponding author: Sivakumar Palanivelu, Tel: +32-(0)9-264.33.15, Fax: +32-(0)9-264.35.87 
electro-mechanical Instron 4505 machine was used for conducting all the quasi-static crushing tests. The load and the corresponding displacement of cross head (equivalent to the deformation length of the test specimen) were captured by automatic data acquisition system. The cross head displacement of $10 \mathrm{~mm} / \mathrm{min}$ was chosen to conduct all the quasi-static tests. For each composite tube series a minimum of four tests has been conducted. Totally 144 tests have been conducted to study the crushing performance of small-scale composite tubes. The crushing characteristics, deformation patterns and the corresponding load-deformation histories of all the composite tube specimens are presented in this section based on their geometry, thickness and their triggering profiles. For the simplification, the compressive load and the compressive deformation length are indicated in positive numbers in all the loaddeformation curves. The scatter in the crushing parameters for all the composite tubes is lower despite using hand lay-up process to manufacture composite tubes. As an example, the load-deformation curves of $2 \mathrm{~mm}$ thickness circular cross sectional composite tubes with triggering type 2 (tulip triggering) are shown in Figure 6.

For all composite tube series, there was no significant difference in the final deformation observed between triggering type 1 and 2. Furthermore, the effect of transverse fibres $\left(\overrightarrow{\mathrm{e}}_{22}\right)$ on the crushing performance of the composite tubes is negligible.

\subsection{Square cross sectional tubes}

\subsection{1. $1 \mathrm{~mm}$ thickness tubes (SST1and SST2)}

The deformation patterns of square tubes (both triggering type 1 and 2) with t/W ratio of 0.045 are shown in Figure 7(a - top) and 7(b - top). Both series of composite tubes (SST1 and SST2) exhibited a catastrophic failure mode due to their geometry and thickness. The initial stages of the crushing showed a progressive crushing of the triggering profiles. However, immediately after the crushing of the triggering profiles a sudden growth of the axial cracks was observed along its entire length. In all eight test specimens (4 test specimens for each triggering) the axial cracks were observed only at the corner locations. This is due to the stress concentration at the corners of the square composite tubes [14, 15]. Furthermore, the axial cracks were formed only at the interface location of one roving to another. This evidence can be clearly noticed from Figure 7(a - top). Due to the sudden growth of the axial cracks, the composite tubes lost their load bearing capacity in the later stages of crushing. As an example, the corresponding load-deformation histories for one specimen of these two composite tubes are shown in Figure 7(b - top). For both tubes the crushing load dropped immediately after the peak crush load. There was an appreciable difference in the peak crush load noticed between triggering type 1 and 2. The peak crush load of triggering type 1 was higher than triggering type 2 . This may be due to the lower stiffness offered by each tulip and the consequent reduction in the strength. The average peak crush load for triggering type 1 was $2.2 \mathrm{kN}$ and the average peak crush load of triggering type 2 was $1.5 \mathrm{kN}$. For triggering type 2, the slope to reach the peak crush load was uniform. For both composite tubes series there was no clear evidence of delamination noticed. Furthermore, there was no difference in the deformation pattern.

\subsection{2. $2 \mathrm{~mm}$ thickness tubes (SDT1and SDT2)}

Similar to $1 \mathrm{~mm}$ thickness tubes, the deformation patterns and the corresponding loaddeformation histories of square tubes with $2 \mathrm{~mm}$ thickness are shown in Figure 7(a - bottom) and 7(b - bottom). Unlike $1 \mathrm{~mm}$ thickness composite tubes, the $2 \mathrm{~mm}$ thickness composite

*Corresponding author: Sivakumar Palanivelu, Tel: +32-(0)9-264.33.15, Fax: +32-(0)9-264.35.87

Email: Sivakumar.Palanivelu@UGent.be 
tubes (SDT1 and SDT2) showed uniform and progressive crushing failure modes throughout their length. For both square tubes, after the circumferential delamination (which occurred at the mid thickness of the tube), due to stress concentrations the primary axial cracks developed along the corners. As a result, each side of the composite tube has split into petals moving inwards and outwards [17, 18]. The major crushing energy of both types of composite tubes was consumed by lamina bending followed by the breakage of resin bonds. The separation of plies from each other occurred at the mid-thickness of the tube wall due to the delamination process. The typical failure modes of brittle composite tubes such as delamination, axial cracks, lamina bending and the fibre fracturing were evident (refer Figure 7(a - bottom) and 7(b - bottom)) throughout the crushing process. The load-deformation histories of these two composite tubes (SDT1 and SDT2) are shown in Figure 7(b - bottom). The load-deformation curves of both composite tubes followed three phases. The first phase was the increase in load at the initial stage of the compression. During this stage the triggering region of the composite tube was completely crushed; subsequently, the circumferential delamination was started. The area under the load-deformation curve up to the peak crush load corresponds to the total energy spent on the initial circumferential delamination of the composite tube. After the circumferential delamination the peak crush load decreased abruptly. This corresponds to the second stage of the crushing. At the end of this second stage a significant amount of energy was consumed by bending of the petals followed by the shear deformation of the plies that led to fibre fracture. The chronological order of the delamination, axial cracks, bending of petals and the shear fracture of the fibre continued for the subsequent stages of the crushing. Due to the above failure modes, the crushing load of the tube oscillated around a mean value. This was the third stage of the crushing. For triggering type 2, due to the triggering tulips the deformation length to reach the major delamination was different from triggering type 1 tubes and so a smaller slope of the peak crush load was observed. Similar to $1 \mathrm{~mm}$ thickness tubes, there was a significant difference in the peak crush load observed between triggering type 1 and type 2. The composite tube with triggering type 1 showed a higher peak crush load than triggering type 2 . Furthermore, for triggering type 1 the load dropped considerably after the peak crush load. However, in case of triggering type 2 the drop in the load after the peak crush load was linear, and lower compared to triggering type 1 . The average peak crush loads were $7.47 \mathrm{kN}$ and $6.225 \mathrm{kN}$ for triggering type 1 and 2 respectively.

\subsection{Circular cross sectional tubes}

\subsection{1. $1 \mathrm{~mm}$ thickness tubes (CST1 and CST2)}

Unlike square tubes with $1 \mathrm{~mm}$ thickness, the circular tubes (CST1 and CST2) showed the controlled progressive failure modes. The progressive deformation patterns and the corresponding load-deformation histories are shown in Figure 8(a - top) and 8(b - top). Though the composite tube was made by a single layer of E-glass fabric, the circumferential delamination started at the mid- wall thickness of the composite tube. This evidence can be noticed from Figure 8(a - top). The longitudinal cut sections of these composite tubes confirmed the same. Consequently, axial cracks were formed parallel to the axis of the tube. The uniform geometry of the circular tube facilitated to form a large number of axial cracks and thus more petals were formed. The major amount of the crushing energy was absorbed due to the increasing number of longitudinal cracks and subsequent bending of the petals [8]. The bending angle of the petals was larger than for the square tubes. This might be due to a lower resistance offered by each petal. During the crushing process a considerable amount of fibre fracturing was also observed. Similar to the square tube the axial cracks were formed

*Corresponding author: Sivakumar Palanivelu, Tel: +32-(0)9-264.33.15, Fax: +32-(0)9-264.35.87

Email: Sivakumar.Palanivelu@UGent.be 
only at the interface location of each roving. The peak crush load for the triggering type 1 was higher than for triggering type 2. The average peak crush loads were $3.095 \mathrm{kN}$ and 2.9 $\mathrm{kN}$ for triggering type 1 and 2 respectively. Due to the triggering profile the peak crush load for triggering type 2 occurred later than for the triggering type 1 . The results from the circular geometry gave a clear indication that even though the composite tube dimensions remain the same (i.e., t/D and t/W ratio for circular and square tubes) the geometry of the composite tube plays a vital role for the progressive crushing.

\subsection{2. $2 \mathrm{~mm}$ thickness tubes (CDT1 and CDT2)}

Similar to $1 \mathrm{~mm}$ thickness circular cross sectional composite tubes, the $2 \mathrm{~mm}$ thickness circular cross sectional composite tubes (CDT1 and CDT2) showed the progressive deformation failure modes. For both tubes the inner and outer petals were formed due to the circumferential delamination. Consequently, the axial cracks were formed parallel to the axis of the tube. The circumferential delamination occurred at the mid-thickness of the tube. Similar to $1 \mathrm{~mm}$ thickness composite tubes more axial cracks were observed. During the crushing process a significant amount of fibre fracturing was also observed. These failure modes can be easily noticed from Figure 8(a - bottom) and 8(b - bottom). These composite tubes (CDT1 and CDT2) showed a very stable and progressive crushing throughout the crushing process. Similar to $1 \mathrm{~mm}$ thickness circular composite tube with triggering type 1 (CST1), the $2 \mathrm{~mm}$ thickness circular composite tube with triggering type 1 (CDT1) showed a sudden drop in the crushing load after the peak crush load. For the triggering type 2 the crushing load remained the same throughout the crushing length which is a good indicator for the better energy absorption. For both series of composite tubes the number of axial cracks varied from 10 to 14 . Similar to square tubes there was a difference in the peak crush load noticed between the triggering type 1 and 2 . The average peak crush loads were $7 \mathrm{kN}$ and $6.35 \mathrm{kN}$ for the triggering type 1 and triggering type 2 respectively.

\subsection{Hexagonal cross sectional tubes}

\subsection{1. $1 \mathrm{~mm}$ thickness tubes (HST1 and HST2)}

The crushing performance of $1 \mathrm{~mm}$ thickness hexagonal cross sectional composite tubes (HST1 and HST2) was very similar to $1 \mathrm{~mm}$ thickness square tubes. A local-kink in the fibres was observed after the crushing of the triggering profile (refer Figure 9(b - top). Subsequently, the longitudinal cracks were initiated and propagated through the entire length of the composite tubes (Figure 9(a - top). However, there was a difference noticed for the location of the axial cracks. For the square tubes with $1 \mathrm{~mm}$ thickness (SST1 and SST2) the axial cracks were formed at the corner locations of the composite tubes consistently. However, in case of hexagonal composite tubes there was no consistency in the location of axial cracks at the corner locations; these locations were changed arbitrarily. Later stages of the crushing process showed a wall buckling mode. This effect can be clearly noticed from Figure 9(b - top). The corresponding load-deformation histories of these composite tubes can be noticed from 9(b - top). Similar to other composite series, there was a significant difference in the peak crush load observed between triggering type 1 and triggering type 2 . The average peak crush loads were $2.52 \mathrm{kN}$ and $2.0 \mathrm{kN}$ for triggering type 1 and triggering type 2 respectively. 


\subsection{2. $2 \mathrm{~mm}$ thickness tubes (HDT1 and HDT2)}

The deformation pattern of the hexagonal cross sectional composite tubes with $2 \mathrm{~mm}$ thickness is shown in Figure 9(a - bottom) and 9(b - bottom). Similar to the square and circular cross sectional composite tubes the hexagonal tubes also exhibited uniform and progressive crushing failure mode. The typical failure modes (circumferential delamination, axial cracks, lamina bending and fibre fracturing) of these composite tubes can be clearly noticed from Figure 9(a - bottom). The number of axial cracks for these cases (HDT1 and HDT2) was limited to six. Unlike $1 \mathrm{~mm}$ thickness hexagonal composite tubes (HST1 and HST2) the $2 \mathrm{~mm}$ thickness hexagonal tubes showed the axial cracks only at the corner locations (refer Figure 9(a - bottom). The stress concentrations at these corner locations of the composite tubes caused the axial cracks. The corresponding load-deformation histories of these composite tubes with triggering type 1 and 2 are shown in Figure 9(b - bottom). The average peak crush loads were $6.30 \mathrm{kN}$ and $5.72 \mathrm{kN}$ for the triggering type 1 and triggering type 2 respectively. Furthermore, the triggering type 2 profile attributed a steady and higher mean crush load than triggering type 1 which resulted into a higher energy absorption.

\subsection{Hourglass type - A shaped (circular cross sectional) tubes}

\subsection{1. $1 \mathrm{~mm}$ thickness tubes (HAST1 and HAST2)}

The deformation behaviour of the hourglass type - A was similar to the circular composite tubes. The hourglass type - A with $1 \mathrm{~mm}$ thickness tubes (HAST1 and HAST2) showed the typical crushing failure modes such as the circumferential delamination, axial cracks, bending of petals and fibre fracturing. However, there was a difference in the amount of fibre fracturing observed for the hourglass type - A composite tubes with triggering type 1 . A considerable amount of fibres showed fracturing at their mid-length of the composite tubes. This was due to the geometrical shape of these composite tubes. The controlled circumferential delamination attributed to the fibres to split into two halves, and consequently folded inwards and outwards. The reduced cross section of the composite tubes at the mid length facilitated the blockage of a large amount of fibres which were folded inwards (refer Figure 10(a - top)). As a result of this phenomenon, there was a significant difference in the load-deformation histories noticed compared to the circular composite tubes with $1 \mathrm{~mm}$ thickness. The mean crush load of these tubes (with triggering type 1) was increased after achieving $20 \mathrm{~mm}$ of deformation length (Figure 10(b - top)). However, for triggering type 2 the tulip profiles attributed to the breakage of the fibres in short length. Due to the latter phenomenon there was no considerable blockage of fibre debris occurred at its mid-length. Therefore, the mean crush load was controlled only by the geometry and hence, the mean load was dropped at its mid-length (Figure 10(b)). Similar to other cases the peak crush load for the triggering type 2 was lower than for triggering type 1 . The average peak crush loads were $3.1 \mathrm{kN}$ and $2.5 \mathrm{kN}$ for the triggering type 1 and 2 respectively.

\subsection{2. $2 \mathrm{~mm}$ thickness tubes (HADT1 and HADT2)}

The crushing behaviour of the hourglass type - A composite tubes with $2 \mathrm{~mm}$ thickness tubes (HADT1 and HADT2) was very similar to the $1 \mathrm{~mm}$ thickness composite tube series (HAST1 and HAST2). The deformation patterns and the crushing performance of these composite tubes are given in Figure 10(a - bottom) and 10(b - bottom). The typical failure patterns are well evident from these figures. Similar to HAST1, there was an increase in mean crush load noticed after $20 \mathrm{~mm}$ of the deformation length for HADT1. The average

*Corresponding author: Sivakumar Palanivelu, Tel: +32-(0)9-264.33.15, Fax: +32-(0)9-264.35.87

Email: Sivakumar.Palanivelu@UGent.be 
peak crush load for these cases was $7 \mathrm{kN}$ and $6.55 \mathrm{kN}$ for HADT1 and HADT2 composite tubes respectively.

\subsection{Hourglass type - B shaped (circular cross sectional) tubes}

\subsection{1. $1 \mathrm{~mm}$ thickness tubes (HBST1 and HBST2)}

The deformation patterns of the hourglass type - B shaped composite tubes with $1 \mathrm{~mm}$ thickness (HBST1 and HBST2) are shown in Figure 11(a - top) and 11(b - top). The crushing behaviour of these tubes was similar to the circular cross sectional composite tubes. Similar to the hourglass type - A tubes, a significant amount of fibre fracturing was also observed (Figure 11(a - top)) due to the reduced cross section. However, due to the gradual reduction in the cross section of the composite tube the increased mean crush load after $20 \mathrm{~mm}$ deformation length was linear. This phenomenon can be noticed for the composite tube with triggering type 1 (HBST1) in Figure 11(b - top). However, for triggering type 2 the tulip profiles attributed to a steady mean crush load (refer Figure 11(b - top)). Similar to other cases, the peak crush load of for triggering type 1 was higher than for the triggering type 2 (Figure 11(b - top)). The average peak crush loads were $2.99 \mathrm{kN}$ and $2.55 \mathrm{kN}$ for triggering type 1 and 2 respectively.

\subsection{2. $2 \mathrm{~mm}$ thickness tube (HBDT1 and HBDT2)}

The deformation pattern and the corresponding load-deformation histories of the hourglass type - B shaped composite tubes (HBDT1 and HBDT2) are shown in Figure 11(a bottom) and 11(b - bottom). The failure patterns of these composite tubes with triggering type 1 and triggering type 2 were very similar to those of the circular composite tubes. Unlike the $1 \mathrm{~mm}$ thickness composite tubes (HBST1 and HBST2), the load-deformation histories of these composite tubes (HBDT1 and HBDT2) showed no increase in the mean crush load due to the geometry. This shows that the hourglass type - B geometry does not play a major role for the mean crush load for the higher $t / D$ ratio composite tubes. However, this conclusion should be verified for other conical angles. In this investigation a conical angle of $5^{\circ}$ was used for this category of tubes (refer Figure 2). The peak crush load of this case showed a significant difference between the triggering type 1 and triggering type 2 . The average peak crush load for these cases are $6.42 \mathrm{kN}$ and $5.52 \mathrm{kN}$ for triggering type 1 and triggering type 2 respectively.

\subsection{Hourglass type - X shaped (circular cross sectional) tubes}

\subsection{1. $1 \mathrm{~mm}$ thickness tubes (HXST1 and HXST2)}

The crushing performance of the HXST1 and HXST2 composite tubes was completely different from the previous cases. These composite tubes showed non-uniform crushing failure modes. The initial stages of the HXST1 and HXST2 showed the progressive crushing of the triggering profile. However, the later stages of crushing showed a growth of axial cracks at the major diameter locations and further propagated throughout their length. This may be due to the higher compressive radial stress at those locations. The number of the axial cracks varied from 2 to 4 for each composite tube. As a result of this phenomenon, each tube segment showed local wall buckling. Due to this effect the crush load was increased considerably. Subsequently, the fibres at the major diameter location were subjected to

*Corresponding author: Sivakumar Palanivelu, Tel: +32-(0)9-264.33.15, Fax: +32-(0)9-264.35.87

Email: Sivakumar.Palanivelu@UGent.be 
fracturing. These failure modes can be observed from Figure 12(a -top). The sequence of the formation of the axial cracks at the major diameter and the subsequent local wall buckling and the fibre fracturing continued to the next major diameter region of the composite tubes. The load-deformation histories of these composite tubes showed a lower peak crush load than any other composite tubes series (Figure 12(b - top)). The reason for the lower magnitude of the peak crush load was due to the absence of the progressive deformation patterns such as delamination and lamina bending. The average peak crush load of these composite tubes with triggering type 1 and triggering type 2 were $1.25 \mathrm{kN}$ and $1.05 \mathrm{kN}$ respectively.

\subsection{2. $2 \mathrm{~mm}$ thickness tubes (HXDT1 and HXDT2)}

The crushing behaviour of $2 \mathrm{~mm}$ thickness composite tubes (HXDT1 and HXDT2) was similar to $1 \mathrm{~mm}$ thickness composite tubes (HXST1 and HXST2). The initial stages of the crushing of these composite tubes showed a clear evidence of delamination between the inner and the outer plies. However, the later stages of the crushing showed no progressive deformation failure modes (refer Figure 12(a - bottom)). Similar to $1 \mathrm{~mm}$ thickness tubes (HXST1 and HXST2), the axial cracks initiated at the major diameter locations of the composite tubes. Consequently, the fibres at the major diameter locations showed local wall buckling followed by fibre fracturing (Figure 12(b - bottom)). During the local wall buckling mode the fibres at the minor diameter location were pulled towards the axis of the composite tube. The process continued throughout its length. The major amount of the energy was absorbed by the local wall buckling mode and the corresponding fibre fracturing mode. As a result, the total absorbed energy for these composite tube series was lower than for other series. For these composite tubes there was no significant difference in the peak crush load noticed for triggering type 1 and triggering type 2. The average peak crush loads were 3.85 $\mathrm{kN}$ and $3.7 \mathrm{kN}$ for triggering type 1 and triggering type 2 respectively.

\subsection{Hourglass type - Y shaped (circular cross sectional) tubes}

\subsection{1. $1 \mathrm{~mm}$ thickness tubes (HYST1 and HYST2)}

The performance of the hourglass type - Y geometry composite tubes (HYST1 and HYST2) was very similar to hourglass type - X geometry tubes. The formation of the axial cracks at the major diameter region due to the compressive radial stress followed by the local wall buckling failure can be noticed from Figure 13(a - top). This process continued and propagated to the other end of the composite tube. Due to their geometry (no alignment of triggering profiles to the direction of compressive loading), there was no delamination failure mode observed for these composite tubes. The peak crush load of these composite tubes corresponded to the formation of the axial cracks at the major diameter regions. Furthermore, the effect of the sequential failure modes of these composite tubes can be easily understood from the load-deformation histories (Figure 13(b - top)). The peak crush load for these cases was lower than for other composite tube series. Furthermore, there was no significant difference in the peak crush load noticed for triggering type 1 and triggering type 2. The average peak crush loads were 1.5 and $1.4 \mathrm{kN}$ for triggering type 1 and 2 respectively.

\subsection{2. $2 \mathrm{~mm}$ thickness tubes (HYDT1 and HYDT2)}

The deformation patterns and the corresponding load-deformation histories of $2 \mathrm{~mm}$ thickness composite tubes (HYDT1 and HYDT2) are shown in Figure 13(a - bottom) and

*Corresponding author: Sivakumar Palanivelu, Tel: +32-(0)9-264.33.15, Fax: +32-(0)9-264.35.87 
13(b - bottom). The failure sequences of these composite tubes were very similar to $1 \mathrm{~mm}$ thickness composite tubes (HYST1 and HYST2). However, there was a significant difference in the peak crush load noticed for triggering type 1 and 2 . The average peak crush loads were $4.6 \mathrm{kN}$ and $3.43 \mathrm{kN}$ for triggering type 1 and 2 respectively.

\subsection{Conical circular type - X}

\subsection{1. $1 \mathrm{~mm}$ thickness tubes (CXST1 and CXST2)}

The crushing performance of these composite tubes (CXST1 and CXST2) was similar to the circular composite tubes. The typical failure patterns of these composite tubes showed the evidence of the circumferential delamination at its mid-thickness, axial cracks, lamina bending and fibre fracturing. The final deformation patterns and the corresponding sequential failure stages are shown in Figure 14(a - top) and 14(b - top). For this type of tubes, there was no significant difference in the peak crush load observed for triggering type 1 and 2 . The average peak crushing loads were $4.0 \mathrm{kN}$ and $3.9 \mathrm{kN}$ for triggering type 1 and 2 respectively. Due to the gradually reduced cross section of the composite tubes (towards the bottom side) the mean crush load was increased after $50 \mathrm{~mm}$ deformation length. Furthermore, a considerable amount of fibre fracturing occurred at the later stages of the crushing process.

\subsection{2. $2 \mathrm{~mm}$ thickness tubes (CXDT1 and CXDT2)}

The deformation patterns and the corresponding load-deformation histories of the conical circular type - X geometry composite tubes with $2 \mathrm{~mm}$ thickness (CXDT1 and CXDT2) are shown in Figure 14(a - bottom) and 14(b - bottom). It can be noticed that the deformation patterns of these composite tubes are similar to the circular tubes (CDT1 and CDT2). However, the peak crush load for these composite tubes (CXDT1 and CXDT2) was higher than for the circular composite tubes. The peak crush load loads were $8.65 \mathrm{kN}$ and $7.65 \mathrm{kN}$ for triggering type 1 and 2 . This may be due to the increased cross section at the triggering ends (refer Figure 2). After reaching the peak crush load, the mean crush load of triggering type 2 tubes (CXDT2) was constant throughout the crushing process. As a result of this process the total absorbed energy of this case was higher than for the triggering type 1 .

\subsection{Conical circular type - $Y$}

\subsection{1. $1 \mathrm{~mm}$ thickness tubes (CYST1 and CYST2)}

The deformation patterns and the corresponding load-deformation curves of CYST1 and CYST2 composite tube series are shown in Figure 15(a - top) and 15(b - top). The conical circular type - Y geometry with triggering type 1 and 2 exhibited progressive crushing failure modes. Similar to other series, the initial circumferential delamination occurred at the mid thickness of the composite tubes. Subsequently, the axial cracks, lamina bending and fibre fracturing were also observed. The initial crushing stages of these composite tubes showed a significant amount of fibre fracturing failure modes. This might be attributed to the reduced cross sectional profile at the initial stages of crushing (Figure 15(a top)). The final length of the crushed fibres was shorter than for other composite tube series. The magnitude of the peak crush load for these cases was higher than for the circular composite tubes. This may be due to a higher t/D ratio (0.052) of these composite tubes at their triggering ends. The peak crush loads were $4.45 \mathrm{kN}$ and $4.1 \mathrm{kN}$ for the triggering type 1 
and 2 respectively. Due to the advantage of the triggering profile the type 2 showed a higher mean crush load. As a result, the total energy absorption for this case (CYST2) was higher than for the triggering type 1 (CYST1).

\subsubsection{2 mm thickness tube (CYDT1 and CYDT2)}

Similar to $1 \mathrm{~mm}$ thickness composite tubes, the deformation patterns and the crushing performance of $2 \mathrm{~mm}$ thickness composite tubes with two types of triggering (CYDT1 and CYDT2) are shown in Figure 15(a - bottom) and 15(b - bottom). The peak crush load of these composite tube series also showed higher values. However, there was no significant difference in the peak crush load noticed between the triggering type 1 and triggering type 2 tube series. The average peak crush loads were $9.34 \mathrm{kN}$ and $9.10 \mathrm{kN}$ for triggering type 1 and 2 respectively. As a result of the higher peak crush load and the corresponding mean crush load, the total absorbed energy for these composite tube series was higher than for other composite tube series.

\section{Comparison of crushing performance parameters}

In order to qualify the different geometry of the composite tubes based on their performance, the crushing parameters are presented and compared in this section. To calculate the energy absorption of each composite tube series a deformation length of $70 \mathrm{~mm}$ was considered for all composite tube series. To understand the energy absorption effectiveness of each composite tube, the specific energy absorption (SEA - normalized with respect to mass) was calculated based on Equation 1.

$$
S E A=\frac{\int_{0}^{l \max } P(l) d l}{m_{t}} \quad(k J / k g)
$$

where $P(l)$ is the instantaneous crushing load corresponding to the instantaneous crushing deformation length $\mathrm{dl} ; l_{\max }$ is the maximum or total deformation length $(70 \mathrm{~mm}) ; m_{t}$ is the mass of each composite tube for $70 \mathrm{~mm}$ length. As we have seen earlier the peak crush load and the mean crush load were significantly influenced by the triggering geometry. Hence the effect of triggering on these performance parameters is also presented. The mean crush load $\left(P_{\text {mean }}\right)$ of each composite tube and the corresponding crushing efficiency $\left(\eta_{c}\right)$ were calculated based on Equation (2) and (3).

$$
\begin{gathered}
P_{\text {mean }}=\frac{\int_{0}^{l_{\max }} P(l) d l}{l_{\max }}(k N) \\
\eta_{c}=\frac{P_{\text {mean }}}{P_{\max }} \times 100 \%
\end{gathered}
$$

where $P_{\max }$ is the peak crush load of each composite tube. The calculated average values (from 4 test specimens for each composite tube series) are given in Table 2. 


\subsection{For $1 \mathrm{~mm}$ thickness composite tube series}

\subsubsection{Effect of tube geometry and triggering type on SEA}

The specific energy absorption of different geometrical shapes of the composite tubes with $1 \mathrm{~mm}$ thickness (for triggering type 1 and 2) is shown in Figure 16(a); and the corresponding average peak crush loads are shown in Figure 16(b). It can be noticed that the scatter of the crushing parameters is low despite using hand lay-up technique for manufacturing the composite tubes; and the corresponding coefficient of variations $\left(\mathrm{C}_{\mathrm{v}}\right.$ percentage ratio of standard deviation to the mean) for peak crush load and SEA are given in Table 2. The square and hexagonal cross sectional tubes with $1 \mathrm{~mm}$ thickness were not considered for the specific energy absorption due to their catastrophic failure. For composite tubes with $1 \mathrm{~mm}$ thickness, the specific energy absorption for the conical circular type - Y was higher than for any other composite tube series. The average maximum value attained by this composite tube series with triggering type 2 was $21.8 \mathrm{~kJ} / \mathrm{kg}$. This value was reduced considerably for triggering type $1(16.20 \mathrm{~kJ} / \mathrm{kg})$. Similarly, the other composite tube series such as circular cross sectional, hourglass type - B, and hourglass type - Y showed similar results (Figure 16(a)). The reason for the higher SEA of triggering type 2 is the higher mean crush load. As a result of this phenomenon the crushing efficiency for the composite tubes with triggering type 2 was higher than for the triggering type 1 (Refer Table 2). However, the hourglass type - A showed no significant difference in SEA for triggering type 1 (15.45 $\mathrm{kJ} / \mathrm{kg}$ ) and type $2(15.14 \mathrm{~kJ} / \mathrm{kg})$. The SEA levels of hourglass type - X (5.14 and $3.63 \mathrm{~kJ} / \mathrm{kg}$ for triggering type 1 and 2 respectively) and hourglass type - Y (4.44 and $6.04 \mathrm{~kJ} / \mathrm{kg}$ for triggering type 1 and 2 respectively) were much lower than other geometrical shapes. The reasons for the lower specific energy absorption were the non-progressive failure modes and the absence of the delamination. The ranking from a higher to a lower specific energy absorption based on the geometry and the triggering for $1 \mathrm{~mm}$ thickness composite tubes is given below.

For triggering type 1: Conical circular type $-\mathrm{Y}>$ Circular cross section $=$ Hourglass type $-\mathrm{A}$ $>$ Hourglass type $-\mathrm{B}=$ Conical circular type $-\mathrm{X}>$ Hourglass type $-\mathrm{X}>$ Hourglass type $-\mathrm{Y}$.

For triggering type 2: Conical circular type - $\mathrm{Y}>$ Conical circular type - $\mathrm{X}>$ Circular cross section $>$ Hourglass type - B > Hourglass type - A > Hourglass type - Y > Hourglass type - X.

\subsubsection{Effect of tube geometry and triggering type on peak crush load}

The effect of tube geometry and the triggering type on the peak crush load can be clearly noticed from Figure 16(b). The conical circular type - Y geometry showed higher peak crush loads (4.45 and $4.10 \mathrm{kN}$ for triggering type 1 and 2) than any other composite tube geometry. The peak crush load of hourglass type - A $(3.10 \mathrm{kN})$ and hourglass type - B (2.99 $\mathrm{kN}$ ) with triggering type 1 can be compared with the circular tube (3.09 $\mathrm{kN})$. Due to the absence of the circumferential delamination, the hourglass type - X and hourglass type - $\mathrm{Y}$ geometrical shapes showed lower peak crush loads. In all tube series the peak crush load for triggering type 2 was lower than for triggering type 1 ; and the corresponding SEA for triggering type 2 tubes is higher than for triggering type 1 (except hourglass type - A and hourglass type - X). This was due to the lower stiffness offered by each tulip during the crushing process followed by short interlaminar cracks. Keeping a lower peak crush load for the inner core member may attribute to achieve the deformation easily during an explosion event and so the magnitude of the peak crush load transferred to the non-sacrificial structure 
can be minimised. Hence, the selection of triggering type 2 geometry would provide appropriate results at a lower peak crush load. From these results an important conclusion can be made. The same geometry of the composite tube can be extended to different (blast) loading requirements by changing the triggering profile. However, the peak crush loads of these profiles and the influence of other parameters have to be studied and confirmed for dynamic load cases.

\subsection{For $2 \mathrm{~mm}$ thickness composite tube series}

\subsubsection{Effect of tube geometry and triggering type on SEA}

The comparison of the specific energy absorption and the corresponding peak crush load distributions are given in Figure 17(a) and 17(b) respectively. It can be noticed that the scatter of the crushing parameters is even lower compared to $1 \mathrm{~mm}$ thickness tubes. Unlike 1 $\mathrm{mm}$ thickness composite tubes the circular cross sectional tube showed a higher specific energy absorption value (35.2 kJ/kg with triggering type 2) than any other composite tube series. The reason for the higher specific energy absorption was higher crush efficiency (75.4 \%). Apart from hourglass type - X and hourglass type - Y, the SEA of hourglass type - A, hourglass type - B, conical circular type - $\mathrm{X}$ and conical circular type - $\mathrm{Y}$ is significantly higher than the standard profiles such as square and hexagonal cross sectional tubes (refer Figure 17(a)). The increased thickness from $1 \mathrm{~mm}$ to $2 \mathrm{~mm}$ for hourglass type - $\mathrm{X}$ and hourglass type - Y has not facilitated to achieve the progressive failure modes. Due to the absence of progressive failure modes and circumferential delamination the SEA of these two tube series is lower. Therefore, these two geometrical shapes can be excluded for further investigations. Similar to $1 \mathrm{~mm}$ thickness tubes, for most cases the SEA for triggering type 2 was higher than for triggering type 1. The ranking from a higher to a lower specific energy absorption based on the geometry and the triggering type for $2 \mathrm{~mm}$ thickness composite tubes is given below.

For triggering type 1: Circular $>$ Conical circular type $-\mathrm{Y}>$ Conical circular type $-\mathrm{X}>$ Hourglass type - A > Hourglass type - B > Hexagonal $>$ Hourglass type $-\mathrm{Y}>$ Square $>$ Hourglass type $-\mathrm{X}$

For triggering type 2: Conical circular type $-\mathrm{Y}>$ Circular tubes $>$ Conical circular type $-\mathrm{X}>$ Hourglass type - B $>$ Hexagonal $>$ Hourglass type $-A>$ Square $>$ Hourglass type $-\mathrm{X}>$ Hourglass type - Y

It can be noticed that the ranking is not the same as for $1 \mathrm{~mm}$ thickness composite tube series. This shows again the influence of the dimensions ( $t / D$ and $t / W)$ of the geometry of the composite tubes on the specific energy absorption.

\subsubsection{Effect of tube geometry and triggering type on peak crush load}

The effect of the tube geometry on the peak crush load can be clearly seen from Figure 17(b). Similar to $1 \mathrm{~mm}$ thickness tubes, the peak crush load for conical circular type $\mathrm{Y}$ was higher than for other tube series $(9.34 \mathrm{kN}$ and $9.10 \mathrm{kN}$ for triggering type 1 and 2 respectively). Due to the absence of delaminations, the peak crush load of hourglass type - $\mathrm{X}$ (3.85 kN and $3.70 \mathrm{kN}$ for triggering type 1 and 2 respectively) and hourglass type - Y (4.60 $\mathrm{kN}$ and $3.43 \mathrm{kN}$ for triggering type 1 and 2 respectively) was lower. The peak crush load of these cases corresponded to the formation of axial cracks at their major diameter location.

*Corresponding author: Sivakumar Palanivelu, Tel: +32-(0)9-264.33.15, Fax: +32-(0)9-264.35.87 
The peak crush load of the hourglass type - A ( $7 \mathrm{kN}$ and $6.55 \mathrm{kN}$ for triggering type 1 and 2 respectively) was comparable with circular cross sectional tube $(7 \mathrm{kN}$ and $6.35 \mathrm{kN}$ for triggering type 1 and 2 respectively). Similar to $1 \mathrm{~mm}$ thickness tubes the peak crush load for triggering type 2 was lower than for triggering type 1 for all composite tube series.

\section{Conclusions}

In this study, the crushing behaviour and the corresponding energy absorption capabilities of small-scale composite tubes have been studied. Nine different geometrical shapes with two different triggering mechanisms ( $45^{\circ}$ chamfering and tulip pattern with an included angle $90^{\circ}$ ) were considered for the study. Furthermore, the effect of dimension (t/D and $\mathrm{t} / \mathrm{W}$ ratio) on each geometrical shape was captured with two different thicknesses ( 1 and $2 \mathrm{~mm}$ ). From the quasi-static experimental results it can be concluded that:

- The circular cross sectional, hourglass type - A, hourglass type - B, conical circular type - X and conical circular type - Y composite tubes with $1 \mathrm{~mm}$ thickness (with triggering type 1 and 2) showed uniform and progressive crushing failure modes. The macro-failure mechanisms associated with these composite tubes were circumferential delamination, axial cracks, lamina bending and fibre fracturing. However, the composite tubes with the standard profiles such as the square and hexagonal cross sections with the same t/W and t/D ratio $(0.045)$ showed a catastrophic failure mode. The major reason for the catastrophic failure was the initiation and sudden propagation of the axial cracks throughout the tube length. This shows that the geometry of the composite tubes plays a significant role for the progressive crushing. Though the hourglass type - X and hourglass type - Y geometrical shapes do not show the catastrophic failure mode, the total energy absorption for these composite tubes was lower than for other tube series. The reason for the lower energy absorption was the absence of the circumferential delamination.

- The square and the hexagonal cross sectional composite tubes with a higher $\mathrm{t} / \mathrm{W}$ and t/D ratio (0.083) showed uniform and progressive crushing failure modes. From these results it can be concluded that in addition to the geometry, the $t / D$ or $t / W$ ratio of a composite tube also plays a major role for uniform and progressive crushing. The increased thickness from $1 \mathrm{~mm}$ to $2 \mathrm{~mm}$ for the hourglass type - X and hourglass type - Y has not facilitated to get all the typical progressive failure patterns of the composite tubes. Similar to $1 \mathrm{~mm}$ thickness composite tubes the hourglass type - X and the hourglass type - Y showed the axial cracks, wall-buckling and the fibre fracturing failure modes.

- Comparison with two different thicknesses and triggering types showed that the consideration of the special geometrical shapes such as the hourglass type - A, hourglass type - B, conical circular type - X and conical circular type - Y will provide higher specific energy absorption values than the standard geometrical profiles such as the square and hexagonal cross sectional tubes. Furthermore, this study has given a clear indication that the hourglass type - $\mathrm{X}$ and the hourglass type - Y can be excluded for further investigations.

- For all composite tube series (both $1 \mathrm{~mm}$ and $2 \mathrm{~mm}$ ) the peak crush load for the composite tubes with triggering type 1 was higher than for triggering type 2 . However, for most cases the crushing efficiency of the triggering type 2 was higher than that of triggering type 1 . This was due to the "flat-topped" shape of the loaddeformation curves of the respective composite tube series due to tulip triggering. 
Furthermore, the specific energy absorption for triggering type 2 profile was significantly higher than for triggering type 1 . The steady mean crush load of the triggering profile (tulips) attributed to a higher specific energy absorption for each case. Hence, the triggering mechanism is an important factor to be considered to achieve good values of the specific energy absorption.

\section{Acknowledgements}

The authors gratefully acknowledge the financial support of the "Fund for Scientific Research” - Flanders (F.W.O) (Grant No: B-07674-03).

\section{References}

1. Kotzialis, C., Derdas C. and Kostopoulos V., Blast behaviour of plates with sacrificial cladding. 5th GRACM International congress on computational mechanics, June 29 July 1, Limassol, Cyprus., 2005.

2. Guruprasad, S. and Mukherjee A., Layered sacrificial claddings under blast loading Part II -- experimental studies. International Journal of Impact Engineering, 2000. 24(9): p. 975-984.

3. Hanssen, A. G., Enstock L. and Langseth M., Close-range blast loading of aluminium foam panels. International Journal of Impact Engineering, 2002. 27(6): p. 593-618.

4. Beardmore, P. and Johnson C. F., The potential for composites in structural automotive applications. Composites Science and Technology, 1986. 26(4): p. 251281.

5. James, A., Performance comparison of plastic composites with metals for vertical body panel applications. SAE Technical paper, 1999. (1999-01-08480).

6. Kostopoulos, V., Markopoulos Y. P., Vlachos D. E., Galiotis C. and Melanitis N. E., A heavy duty composite bridge made of glass polyester pultruded box beams. Proceedings of RTO Applied Vehicle Technology Panel (AVT) Specialists' meeting on "Low cost composite structures". Loen, Norway, May 7-11., 2001.

7. Ramakrishna, S., Microstructural design of composite materials for crashworthy structural applications. Materials \& Design, 1997. 18(3): p. 167-173.

8. $\quad$ Solaimurugan, S. and Velmurugan R., Progressive crushing of stitched glass/polyester composite cylindrical shells. Composites Science and Technology, 2007. 67(3-4): p. 422-437.

9. Hull, D., A unified approach to progressive crushing of fibre-reinforced composite tubes. Composites Science and Technology, 1991. 40(4): p. 377-421.

10. Fairfull, A. H. H., D., Effect of specimen dimensions on the specific energy absorption of fibre composite tubes. In Proceedings of ICCM-VI, 1987: p. 3.36-3.45.

11. Farely, G. L., Effect of specimen geometry on the energy absorption of composite materials. Journal of Composite Materials, 1986. 20: p. 390.

12. Thronton, P. H. E., P.J, Energy absorption in composite tubes. Journal of Composite Matter, 1982. 16: p. 521-545.

13. Thronton, P. H., Harwood,J.J \& Beardmore,P, Fiber reinforced plastic composites for energy absorption purposes. Composite Science Technology, 1985. 24: p. 275-298.

14. Mamalis, A. G., Manolakos D. E., Ioannidis M. B. and Papapostolou D. P., On the response of thin-walled CFRP composite tubular components subjected to static and dynamic axial compressive loading: experimental. Composite Structures, 2005. 69(4): p. 407-420. 
15. Mamalis, A. G., Robinson M., Manolakos D. E., Demosthenous G. A., Ioannidis M. B. and Carruthers J., Crashworthy capability of composite material structures. Composite Structures, 1997. 37(2): p. 109-134.

16. Jimenez. M. A, M. A., Larrode. E, Revuelta. D, Effect of trigger geometry on energy absorption in composite profiles. Composite Structures, 2000. 48(1-3): p. 107-111.

17. Mamalis, A. G., Manolakos D. E., Demosthenous G. A. and Ioannidis M. B., Energy absorption capability of fibreglass composite square frusta subjected to static and dynamic axial collapse. Thin-Walled Structures, 1996. 25(4): p. 269-295.

18. Farely, G. L., Energy absorption of composite materials Journal of Composite Materials, 1983. 17: p. 167.

19. Hamada, H., Coppola J. C., Hull D., Maekawa Z. and Sato H., Comparison of energy absorption of carbon/epoxy and carbon/PEEK composite tubes. Composites, 1992. 23(4): p. 245-252.

20. Mamalis, A. G., Manolakos D. E., Ioannidis M. B. and Papapostolou D. P., On the experimental investigation of crash energy absorption in laminate splaying collapse mode of FRP tubular components. Composite Structures, 2005. 70(4): p. 413-429.

21. Thornton, P. H., The crush behavior of pultruded tubes at high strain rates. Journal of Composite Materials, 1989. 24: p. 22.

22. Mamalis, A. G., Manolakos D. E., Demosthenous G. A. and Ioannidis M. B., The static and dynamic axial collapse of fibreglass composite automotive frame rails. Composite Structures, 1996. 34(1): p. 77-90.

23. Farley, G. L. A. J., R.M, Crushing characteristics of composite tubes with "near elliptical" cross sections. Journal of Composite Materials, 1992. 26: p. 1252.

24. Elgalai, A. M., Mahdi E., Hamouda A. M. S. and Sahari B. S., Crushing response of composite corrugated tubes to quasi-static axial loading. Composite Structures, 2004. 66(1-4): p. 665-671.

25. Zarei, H., Kröger M. and Albertsen H., An experimental and numerical crashworthiness investigation of thermoplastic composite crash boxes. Composite Structures, 2008. 85(3): p. 245-257.

26. Abdewi, E. F., Sulaiman S., Hamouda A. M. S. and Mahdi E., Quasi-static axial and lateral crushing of radial corrugated composite tubes. Thin-Walled Structures, 2008. 46(3): p. 320-332.

27. Farely, G. L., Effect of fibre and matrix maximum strain rate on the energy absorption of composite materials. Journal of Composite Materials, 1986. 20: p. 322.

28. Hamada, H. and Ramakrishna S., Scaling effects in the energy absorption of carbonfiber/PEEK composite tubes. Composites Science and Technology, 1995. 55(3): p. 211-221.

29. Dormegnie. D, Coutellier. D, Delsart. D and E D., Studies of Scale Effects for Crash on Laminated structures. Applied composite materials, 2003. 10: p. 49-61.

30. Thronton, P. H., Energy absorption in composite structures. Journal of Composite Materials, 1979. 13(247).

31. Palanivelu, S., Van Paepegem W., Degrieck J., Van Ackeren J., Kakogiannis D., Van Hemelrijck D., Wastiels J. and Vantomme J., Experimental study on the axial crushing behaviour of pultruded composite tubes. Polymer Testing. 29(2): p. 224-234. 
TABLES

Table 1: Nomenclature, geometry and dimensional details of the composite tube series.

\begin{tabular}{|c|c|c|c|c|c|}
\hline S.No & $\begin{array}{l}\text { Tube } \\
\text { series }\end{array}$ & Cross section / Geometry of the composite tube & $\begin{array}{c}\text { t/D or } \\
t / W \text { ratio }\end{array}$ & $\begin{array}{l}\text { Length) } \\
\text { (mm) }\end{array}$ & $\begin{array}{c}\rho_{\text {linear }} \\
(\mathbf{g} / \mathbf{m m})\end{array}$ \\
\hline \multicolumn{6}{|c|}{ Wall thickness of the tube $1 \mathrm{~mm}$} \\
\hline 1 & SST1 & Square cross sectional tube with triggering type 1 & \multirow{2}{*}{0.045} & \multirow{18}{*}{100} & 0.1232 \\
\hline 2 & SST2 & Square cross sectional tube with triggering type 2 & & & 0.1229 \\
\hline 3 & CST1 & Circular cross sectional tube with triggering type 1 & \multirow{2}{*}{0.045} & & 0.0993 \\
\hline 4 & CST2 & Circular cross sectional tube with triggering type 2 & & & 0.0947 \\
\hline 5 & HST1 & Hexagonal cross sectional tube with triggering type 1 & \multirow{2}{*}{0.045} & & 0.1018 \\
\hline 6 & HST2 & Hexagonal cross sectional tube with triggering type 2 & & & 0.1025 \\
\hline 7 & HAST1 & Hourglass type - A with triggering type 1 & \multirow{2}{*}{0.043} & & 0.1050 \\
\hline 8 & HAST2 & Hourglass type - A with triggering type 2 & & & 0.1011 \\
\hline 9 & HBST1 & Hourglass type - B with triggering type 1 & \multirow{2}{*}{0.045} & & 0.0895 \\
\hline 10 & HBST2 & Hourglass type - B with triggering type 2 & & & 0.0883 \\
\hline 11 & HXST1 & Hourglass type - X with triggering type 1 & \multirow{2}{*}{0.043} & & 0.1078 \\
\hline 12 & HXST2 & Hourglass type - X with triggering type 2 & & & 0.0984 \\
\hline 13 & HYST1 & Hourglass type - Y with triggering type 1 & \multirow{2}{*}{0.046} & & 0.1041 \\
\hline 14 & HYST2 & Hourglass type - Y with triggering type 2 & & & 0.1118 \\
\hline 15 & CXST1 & Conical circular type - $\mathrm{X}$ with triggering type 1 & \multirow{2}{*}{0.045} & & 0.1208 \\
\hline 16 & CXST2 & Conical circular type $-X$ with triggering type 2 & & & 0.1225 \\
\hline 17 & CYST1 & Conical circular type - Y with triggering type 1 & \multirow{2}{*}{0.045} & & 0.1244 \\
\hline 18 & CYST2 & Conical circular type - Y with triggering type 2 & & & 0.1139 \\
\hline \multicolumn{6}{|c|}{ Wall thickness of the tube $2 \mathrm{~mm}$} \\
\hline 19 & SDT1 & Square cross sectional tube with triggering type 1 & \multirow{2}{*}{0.083} & \multirow{18}{*}{100} & 0.2005 \\
\hline 20 & SDT2 & Square cross sectional tube with triggering type 2 & & & 0.2084 \\
\hline 21 & CDT1 & Circular cross sectional tube with triggering type 1 & \multirow{2}{*}{0.083} & & 0.1668 \\
\hline 22 & CDT2 & Circular cross sectional tube with triggering type 2 & & & 0.1598 \\
\hline 23 & HDT1 & Hexagonal cross sectional tube with triggering type 1 & \multirow{2}{*}{0.083} & & 0.1670 \\
\hline 24 & HDT2 & Hexagonal cross sectional tube with triggering type 2 & & & 0.1596 \\
\hline 25 & HADT1 & Hourglass type - A with triggering type 1 & \multirow{2}{*}{0.08} & & 0.1886 \\
\hline 26 & HADT2 & Hourglass type - A with triggering type 2 & & & 0.1826 \\
\hline 27 & HBDT1 & Hourglass type - B with triggering type 1 & \multirow{2}{*}{0.083} & & 0.1552 \\
\hline 28 & HBDT2 & Hourglass type - B with triggering type 2 & & & 0.1534 \\
\hline 29 & HXDT1 & Hourglass type - X with triggering type 1 & \multirow{2}{*}{0.08} & & 0.1682 \\
\hline 30 & HXDT2 & Hourglass type - X with triggering type 2 & & & 0.1633 \\
\hline 31 & HYDT1 & Hourglass type - Y with triggering type 1 & \multirow{2}{*}{0.084} & & 0.1601 \\
\hline 32 & HYDT2 & Hourglass type - Y with triggering type 2 & & & 0.1679 \\
\hline 33 & CXDT1 & Conical circular type - $\mathrm{X}$ with triggering type 1 & \multirow{2}{*}{0.083} & & 0.1988 \\
\hline 34 & CXDT2 & Conical circular type - $\mathrm{X}$ with triggering type 2 & & & 0.1884 \\
\hline 35 & CYDT1 & Conical circular type - Y with triggering type 1 & \multirow{2}{*}{0.083} & & 0.2006 \\
\hline 36 & CYDT2 & Conical circular type - Y with triggering type 2 & & & 0.1856 \\
\hline
\end{tabular}

(Example of the nomenclature of the circular cross sectional composite tube: CST1- Circular, Single ply (1 mm thick) and Triggering type 1; CDT2 - Circular, Double plies (2 mm thick) and Triggering type 2) 
Table 2: Summary of the average crushing parameters of all composite tube series.

\begin{tabular}{|c|c|c|c|c|c|c|c|c|c|c|c|c|c|c|}
\hline \multirow[b]{2}{*}{$\begin{array}{l}\text { Tube cross } \\
\text { section / } \\
\text { geometrical } \\
\text { shapes }\end{array}$} & \multicolumn{7}{|c|}{$1 \mathrm{~mm}$ thickness } & \multicolumn{7}{|c|}{$2 \mathrm{~mm}$ thickness } \\
\hline & $\begin{array}{l}\text { Tube } \\
\text { series }\end{array}$ & $\eta_{c}(\%)$ & $\begin{array}{l}\text { Mean } \\
\text { load } \\
(\mathrm{kN})\end{array}$ & $\begin{array}{l}\text { Peak } \\
\text { load } \\
(\mathrm{kN})\end{array}$ & $\begin{array}{l}\mathrm{C}_{\mathrm{v}} \text { for } \\
\text { peak } \\
\text { load } \\
(\%)\end{array}$ & $\begin{array}{c}\text { SEA } \\
(\mathrm{kJ} / \mathrm{kg})\end{array}$ & $\begin{array}{c}\mathrm{C}_{\mathrm{v}} \\
\text { for } \\
\text { SEA } \\
(\%)\end{array}$ & $\begin{array}{l}\text { Tube } \\
\text { series }\end{array}$ & $\eta_{\mathrm{c}}(\%)$ & $\begin{array}{l}\text { Mean } \\
\text { load } \\
(\mathrm{kN})\end{array}$ & $\begin{array}{l}\text { Peak } \\
\text { load } \\
(\mathrm{kN})\end{array}$ & $\begin{array}{l}\mathrm{C}_{\mathrm{v}} \text { for } \\
\text { peak } \\
\text { load } \\
(\%)\end{array}$ & $\begin{array}{c}\text { SEA } \\
(\mathrm{kJ} / \mathrm{kg})\end{array}$ & $\begin{array}{c}\mathrm{C}_{\mathrm{v}} \\
\text { for } \\
\text { SEA } \\
(\%)\end{array}$ \\
\hline \multirow{2}{*}{$\begin{array}{r}\text { Square } \\
\text { cross section }\end{array}$} & SST1 & - & - & 2.22 & 12.6 & - & - & SDT1 & 33.0 & 2.46 & 7.47 & 7.0 & 12.3 & 12.7 \\
\hline & SST2 & - & - & 1.50 & 16.6 & - & - & SDT2 & 53.1 & 3.43 & 6.22 & 4.5 & 16.2 & 9.5 \\
\hline \multirow{2}{*}{$\begin{array}{r}\text { Circular } \\
\text { cross section }\end{array}$} & CST1 & 51.1 & 1.58 & 3.09 & 9.6 & 15.90 & 10.1 & CDT1 & 70.0 & 4.90 & 7.00 & 8.5 & 30.4 & 4.2 \\
\hline & CST2 & 55.7 & 1.61 & 2.90 & 7.0 & 17.00 & 8.8 & CDT2 & 75.4 & 5.21 & 6.35 & 9.4 & 35.2 & 4.6 \\
\hline \multirow{2}{*}{$\begin{array}{r}\text { Hexagonal } \\
\text { cross section }\end{array}$} & HST1 & - & - & 2.52 & 10.0 & - & - & HDT1 & 43.3 & 2.73 & 6.30 & 9.5 & 16.4 & 13.4 \\
\hline & HST2 & - & - & 2.00 & 12.5 & - & - & HDT2 & 48.4 & 2.77 & 5.72 & 5.0 & 17.4 & 12.7 \\
\hline \multirow{2}{*}{$\begin{array}{l}\text { Hourglass } \\
\text { type - A }\end{array}$} & HAST1 & 53.5 & 1.66 & 3.10 & 6.7 & 15.45 & 7.7 & HADT1 & 56.9 & 3.98 & 7.00 & 6.0 & 21.1 & 4.5 \\
\hline & HAST2 & 54.0 & 1.35 & 2.50 & 16.0 & 15.14 & 9.2 & HADT2 & 45.0 & 2.95 & 6.55 & 8.3 & 18.2 & 6.7 \\
\hline \multirow{2}{*}{$\begin{array}{r}\text { Hourglass } \\
\text { type - B }\end{array}$} & HBST1 & 39.5 & 1.18 & 2.99 & 7.0 & 13.21 & 9.8 & HBDT1 & 54.4 & 3.49 & 6.42 & 7.4 & 20.1 & 6.8 \\
\hline & HBST2 & 51.9 & 1.35 & 2.55 & 13.7 & 15.20 & 6.5 & HBDT2 & 60.1 & 3.32 & 5.52 & 6.1 & 22.6 & 7.1 \\
\hline \multirow{2}{*}{$\begin{array}{l}\text { Hourglass } \\
\text { type - X }\end{array}$} & HXST1 & 44.0 & 0.55 & 1.25 & 18.0 & 5.14 & 34 & HXDT1 & 30.4 & 1.17 & 3.85 & 17.0 & 6.96 & 30.0 \\
\hline & HXST2 & 31.8 & 0.35 & 1.05 & 15.2 & 3.63 & 58 & HXDT2 & 50.5 & 1.87 & 3.70 & 12.0 & 11.4 & 26.0 \\
\hline \multirow{2}{*}{$\begin{array}{l}\text { Hourglass } \\
\text { type - Y }\end{array}$} & HYST1 & 30.6 & 0.46 & 1.50 & 17.7 & 4.44 & 45 & HYDT1 & 45.4 & 2.09 & 4.60 & 14.0 & 13.0 & 17.8 \\
\hline & HYST2 & 47.8 & 0.67 & 1.40 & 23.0 & 6.04 & 41 & HYDT2 & 43.7 & 1.50 & 3.43 & 12.6 & 8.94 & 26.8 \\
\hline \multirow{2}{*}{$\begin{array}{r}\text { Conical } \\
\text { circular } \\
\text { type - X }\end{array}$} & CXST1 & 40.0 & 1.59 & 4.00 & 8.8 & 13.19 & 15 & CXDT1 & 54.0 & 4.67 & 8.65 & 4.3 & 23.5 & 5.8 \\
\hline & CXST2 & 54.3 & 2.12 & 3.90 & 8.0 & 17.30 & 9.2 & CXDT2 & 66.4 & 5.08 & 7.65 & 4.7 & 26.9 & 6.7 \\
\hline \multirow{2}{*}{$\begin{array}{r}\text { Conical circular } \\
\text { type }-\mathrm{Y}\end{array}$} & CYST1 & 45.2 & 2.01 & 4.45 & 6.0 & 16.20 & 8.3 & CYDT1 & 61.9 & 5.78 & 9.34 & 4.1 & 28.8 & 4.1 \\
\hline & CYST2 & 60.7 & 2.49 & 4.10 & 5.4 & 21.80 & 7.6 & CYDT2 & 64.3 & 5.85 & 9.10 & 4.9 & 31.5 & 4.3 \\
\hline
\end{tabular}

\section{FIGURES}

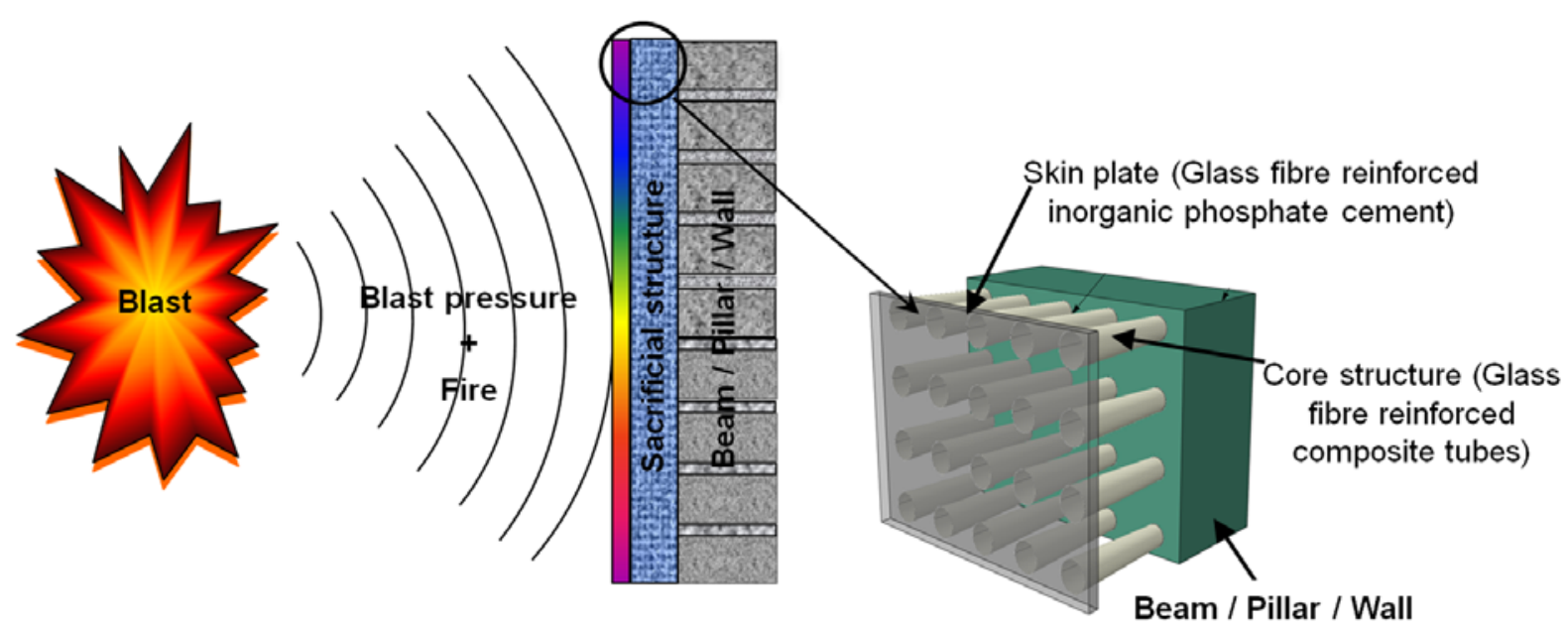

Figure 1: Concept of proposed sacrificial cladding structure.

*Corresponding author: Sivakumar Palanivelu, Tel: +32-(0)9-264.33.15, Fax: +32-(0)9-264.35.87 


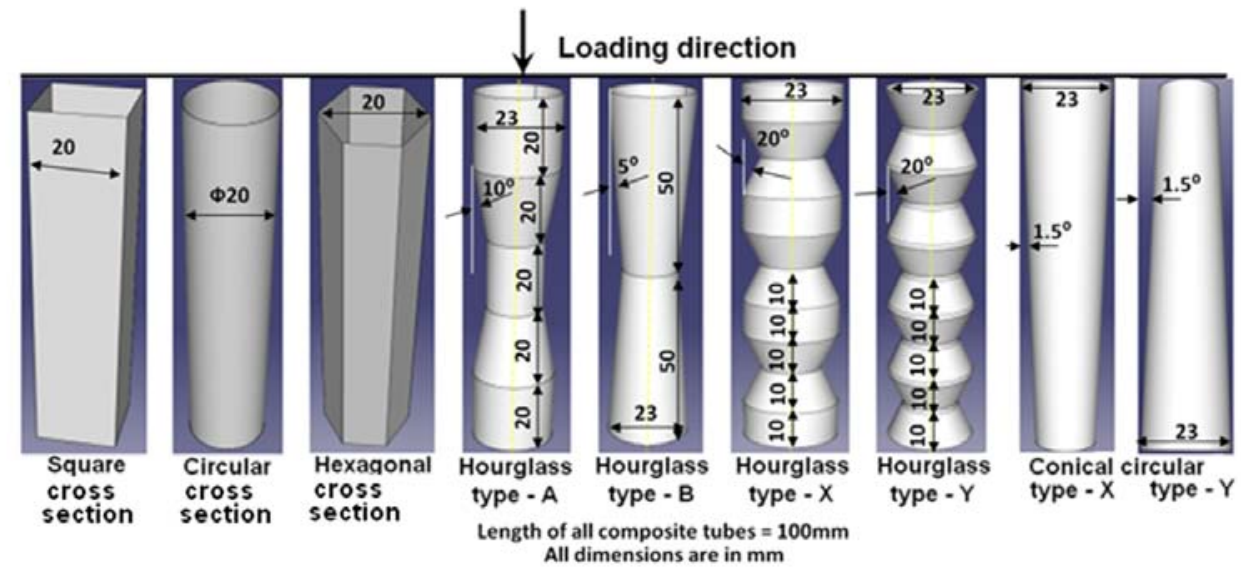

Figure 2: Details of the cross sections, geometry and the (inner) dimensions of the composite tubes

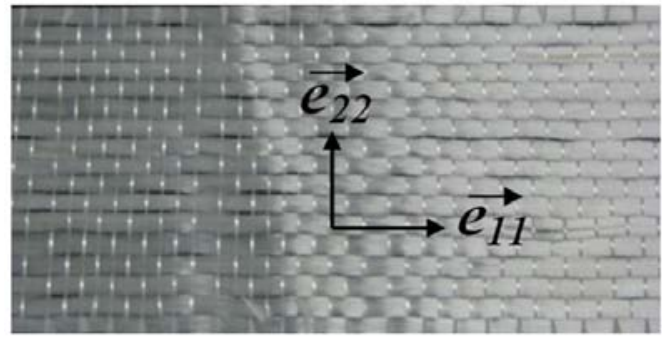

(a) Unidirectional E-glass fabric.
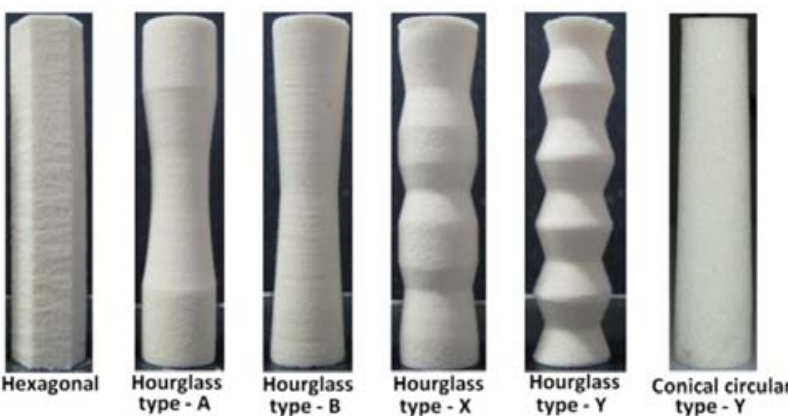

(b) Fxample of polyurethane foan

Figure 3: Uni-directional E-glass fabric and finished polyurethane foam mandrels.

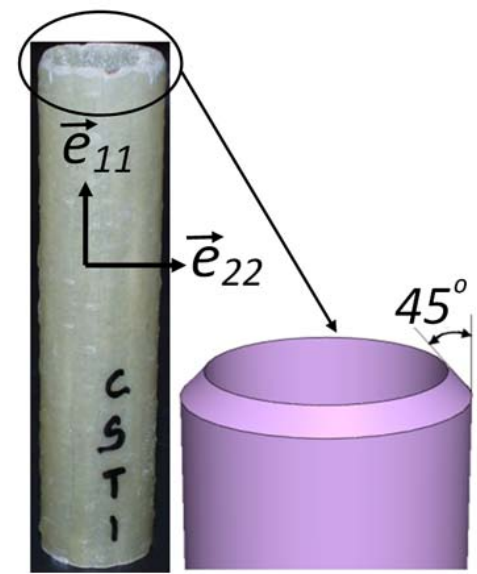

(a) Triggering type 1

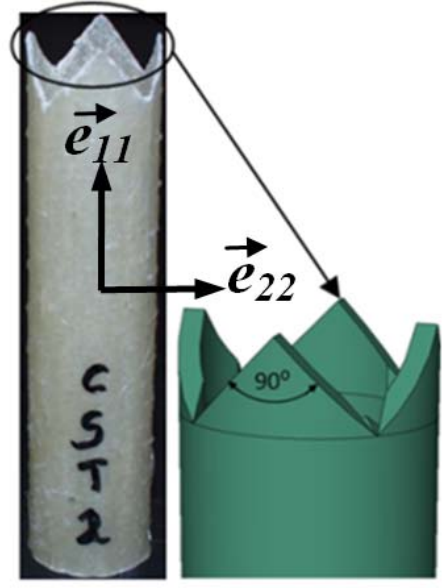

(b) Triggering type 2

Figure 4: Details of triggering. 


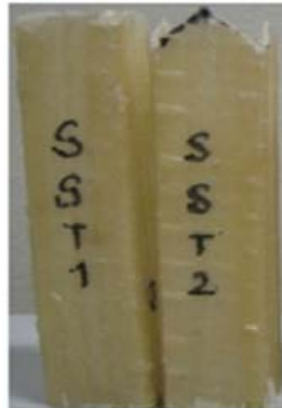

Square cross sectional

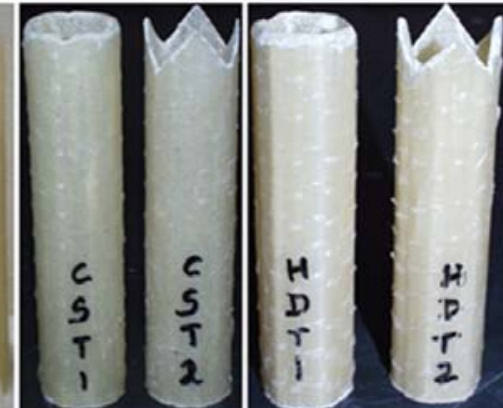

Circular cross sectional
Hexagonal cross sectional

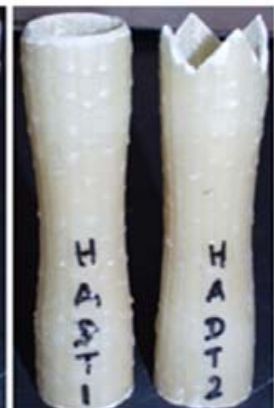

Hourglass type - A

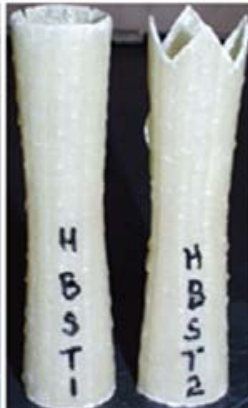

Hourglass type - B

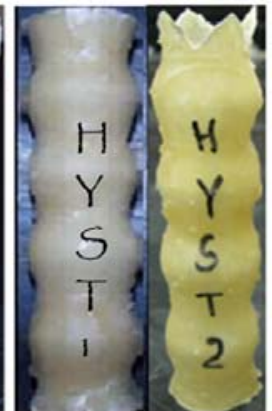

Hourglass type - Y

Figure 5: Examples of finished composite tube specimens with triggering.

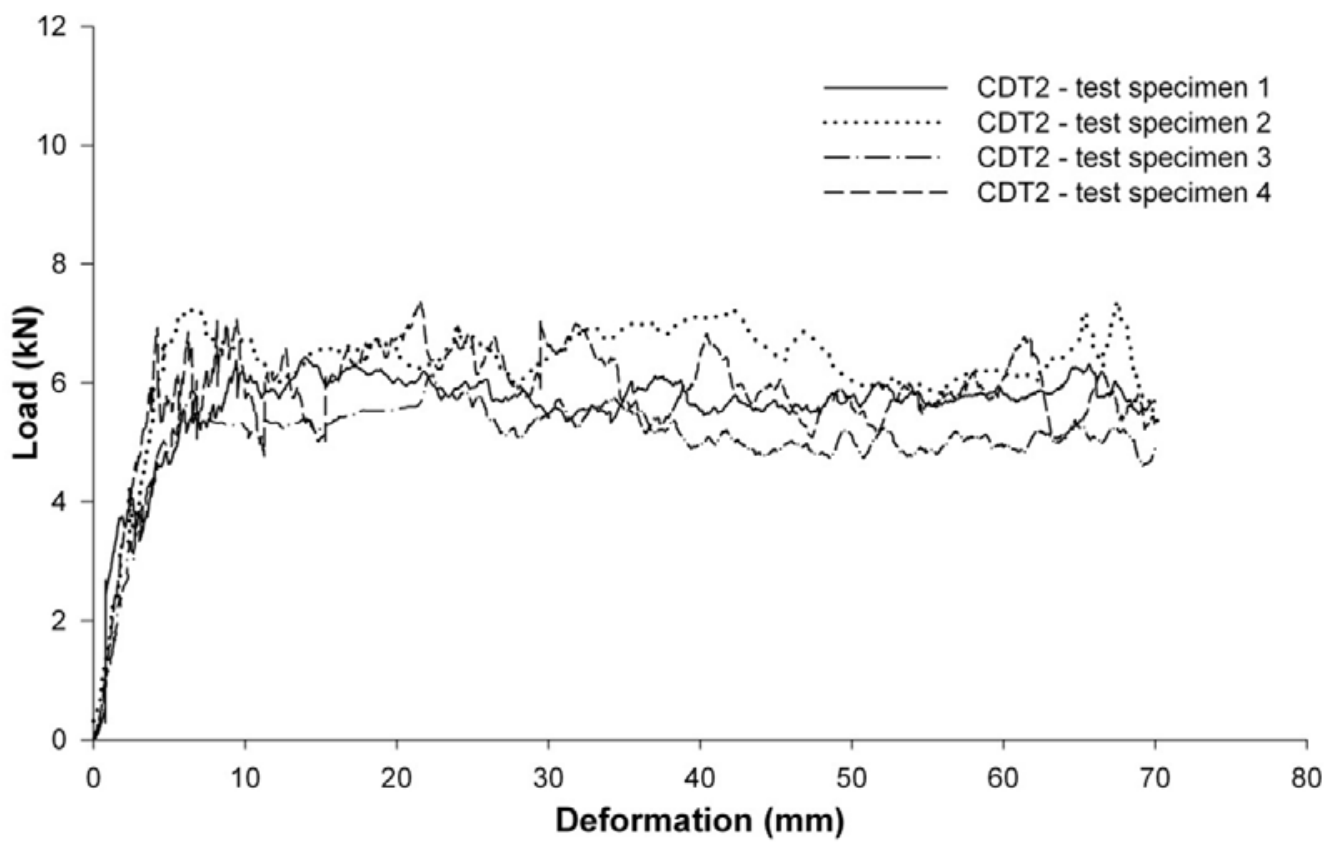

Figure 6: Example of a limited scattering of crushing characteristics of $2 \mathrm{~mm}$ thickness circular cross sectional composite tubes with triggering type 2 (tulip triggering). 

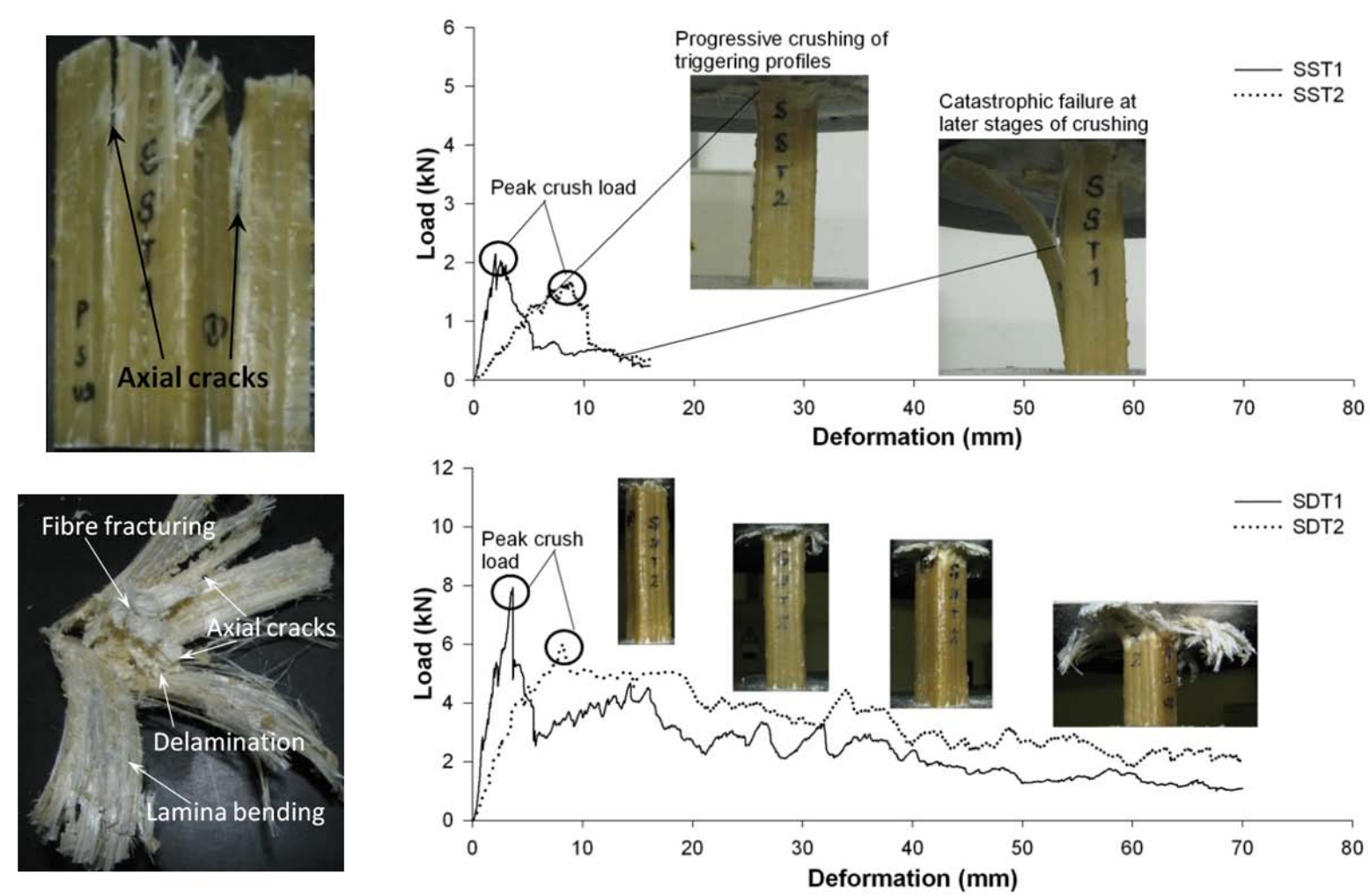

(a) Final deformation patterns (top - SST1; bottom - SDT2).

(b) Load - deformation histories (top - SST1 and SST2; bottom - SDT1 and SDT2).

Figure 7 : Deformation patterns and the crushing performance of the square cross sectional composite tubes.
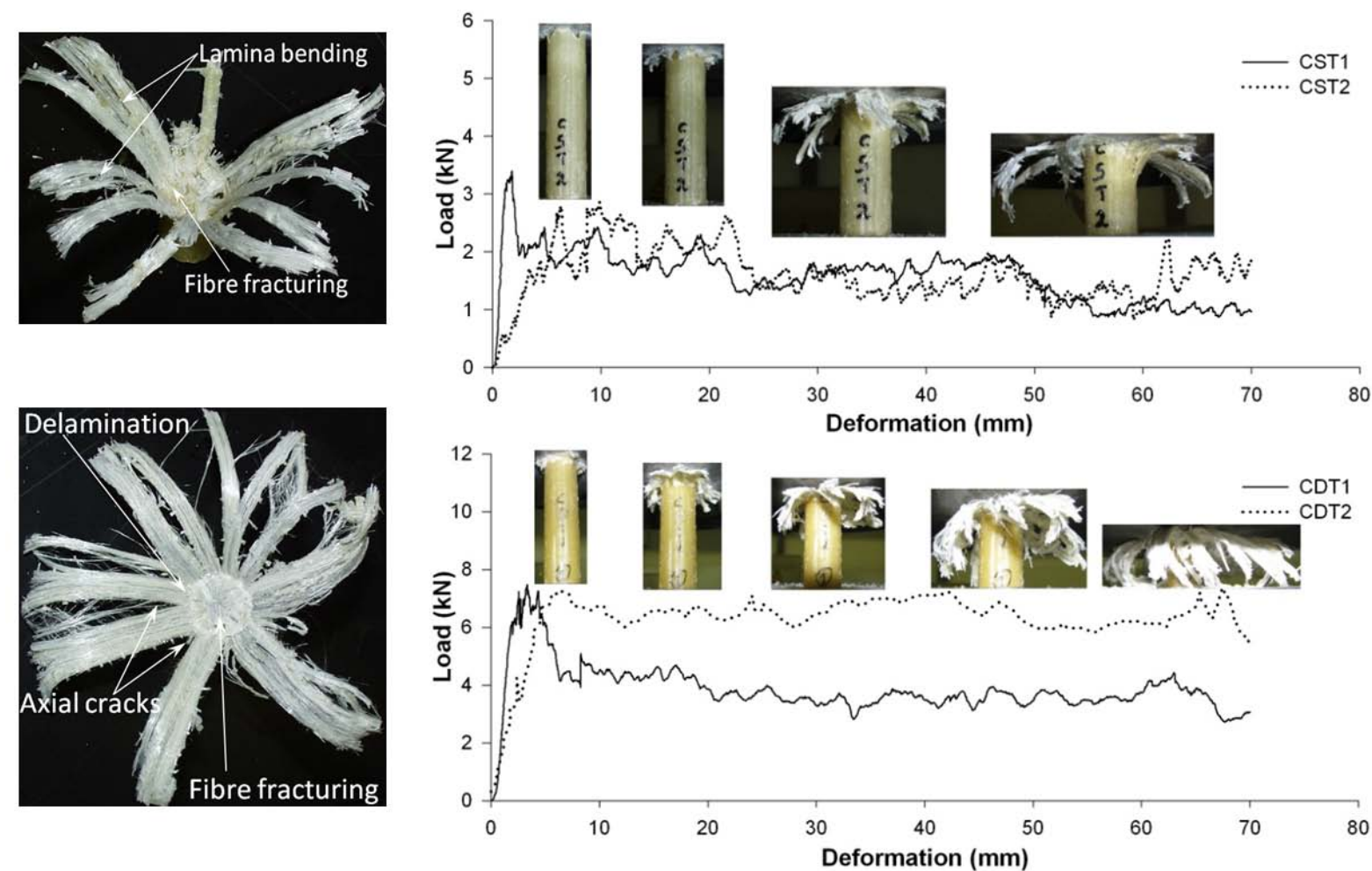

(a) Final deformation patterns (top - CST2; bottom - CDT1).

(b) Load - deformation histories (top - CST1 and CST2; bottom - CDT1 and CDT2).

Figure 8: Deformation patterns and the crushing performance of the circular cross sectional composite tubes. 

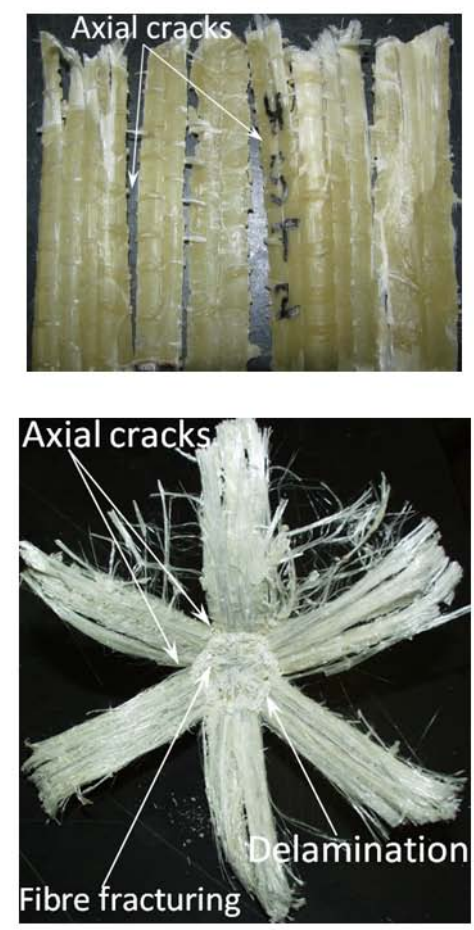

(a) Final deformation patterns (top - HST2; bottom - HDT1)

Figure 9: Deformation patterns and the crushing performance of the hexagonal cross sectional composite tubes.
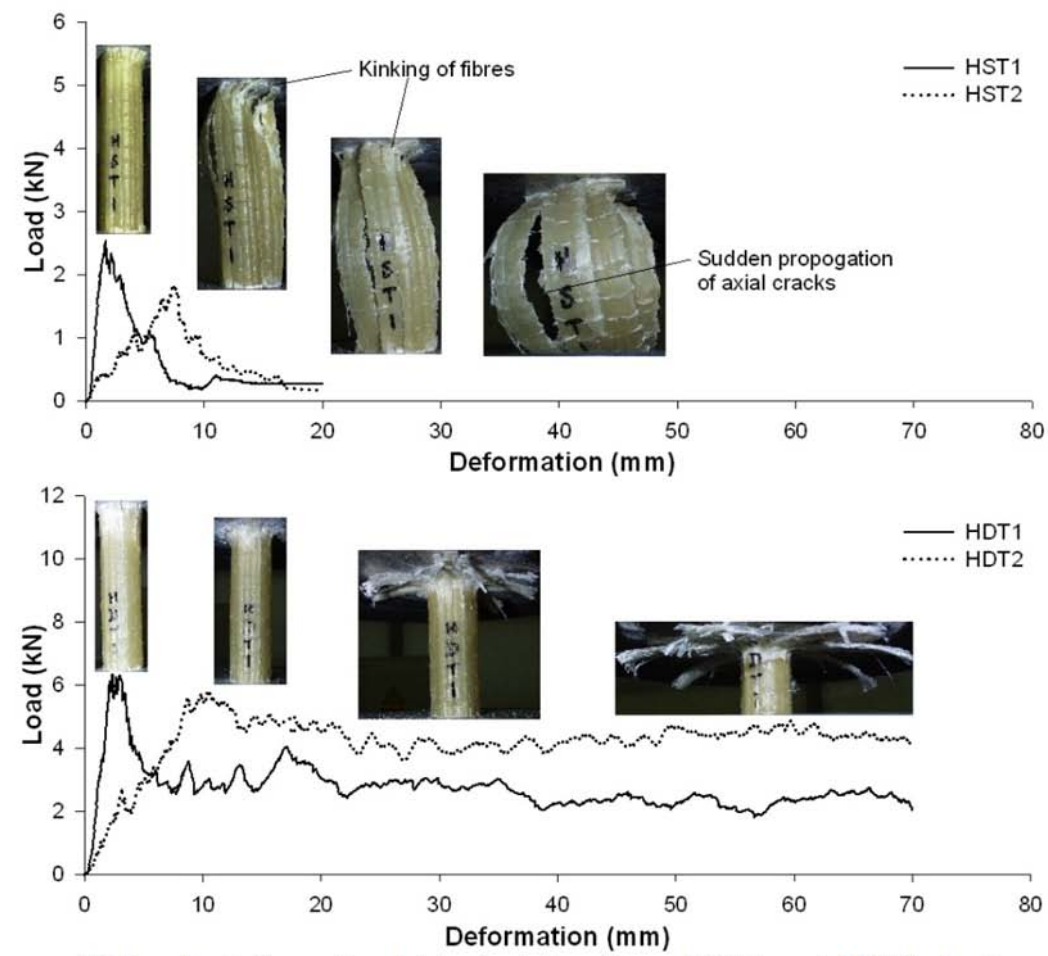

(b) Load - deformation histories tubes (top - HST1 and HST2; bottom HDT1 and HDT2).
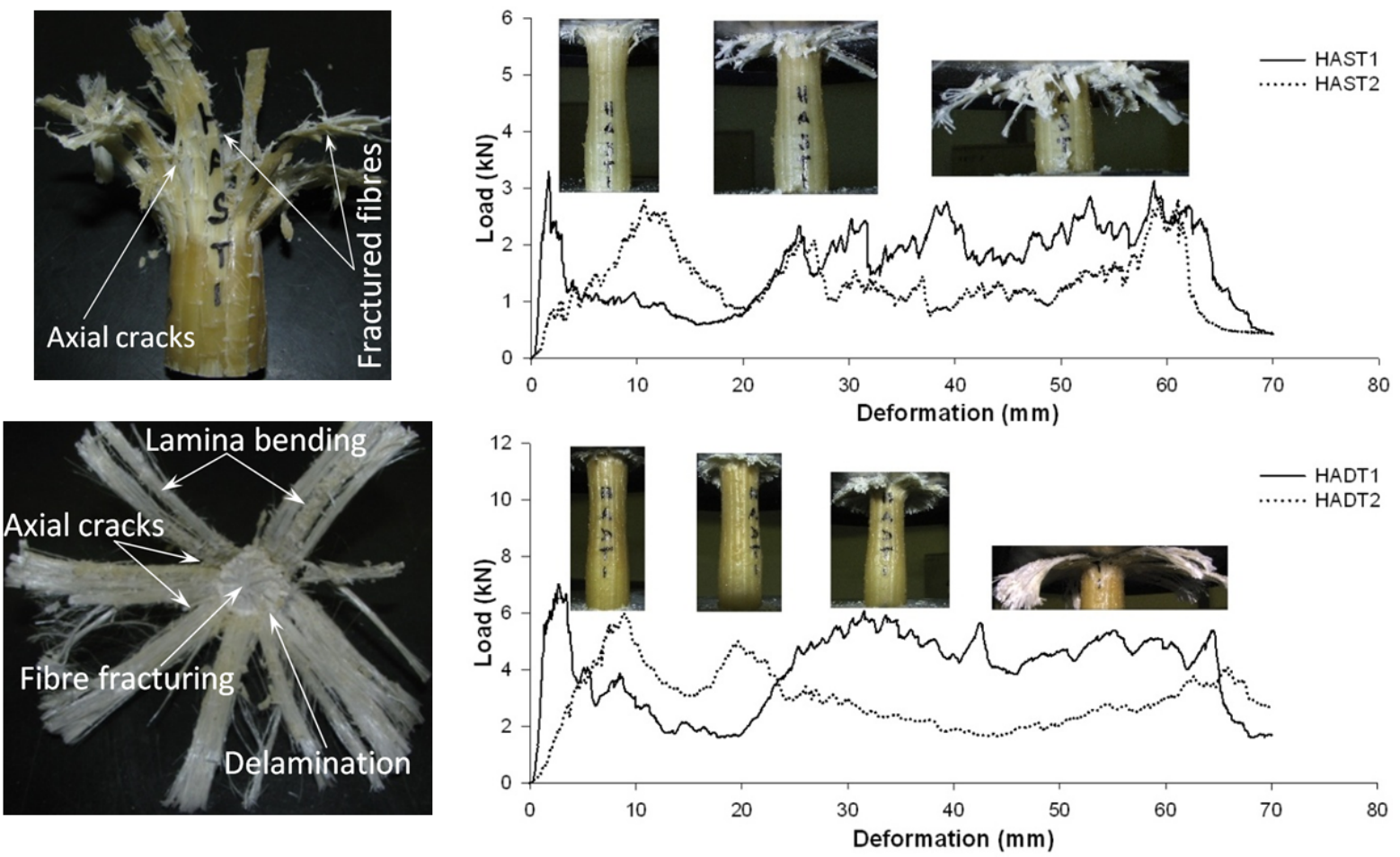

(a) Final deformation patterns (top - HAST1; bottom - HADT2).

(b) Load - deformation histories (top - HAST1 and HAST2; bottom HADT1 and HADT2).

Figure 10: Deformation patterns and the crushing performance of the hourglass type - A shaped composite tubes.

*Corresponding author: Sivakumar Palanivelu, Tel: +32-(0)9-264.33.15, Fax: +32-(0)9-264.35.87 

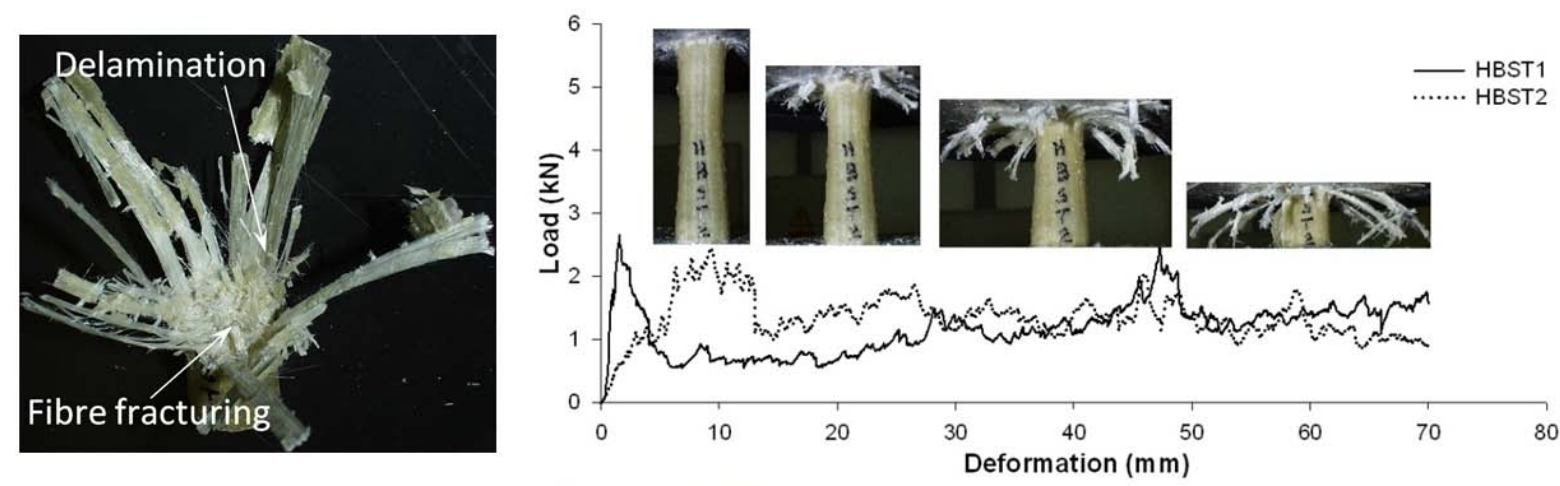

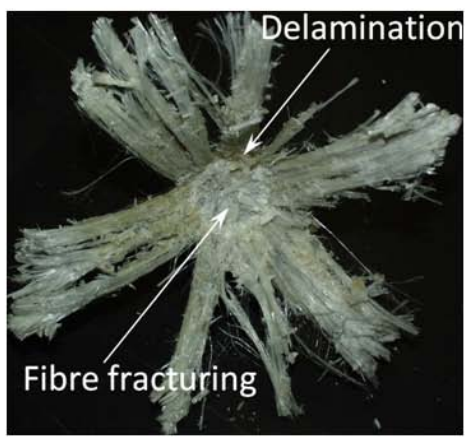

(a) Final deformation patterns (top - HBST1; bottom - HBDT2)

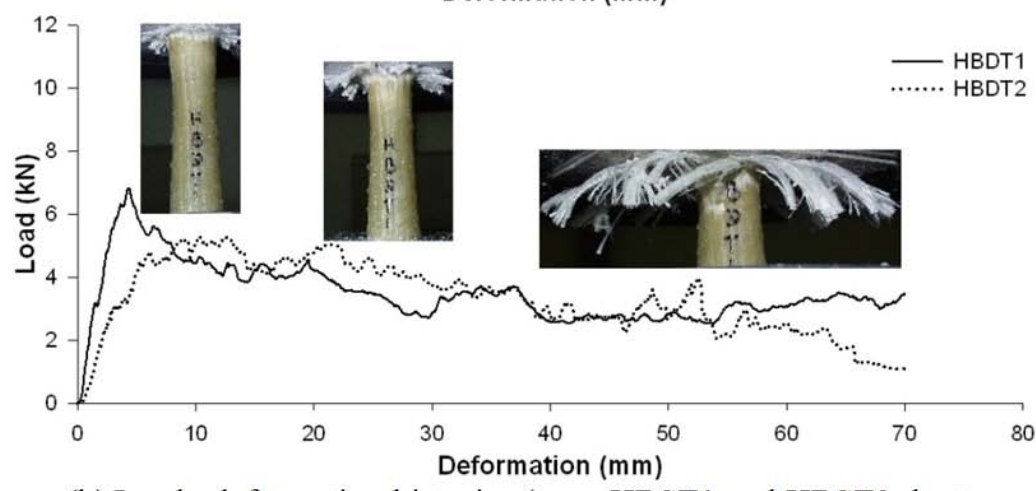

(b) Load - deformation histories (top - HBST1 and HBST2; bottom HBDT1 and HBDT2).

Figure 11: Deformation patterns and the crushing performance of the hourglass type - B shaped composite tubes.
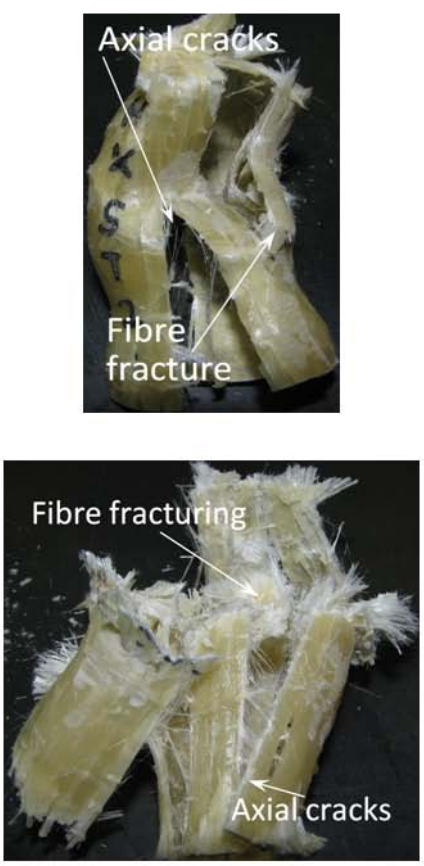

(a) Final deformation patterns (top - HXST1; bottom - HXDT2).
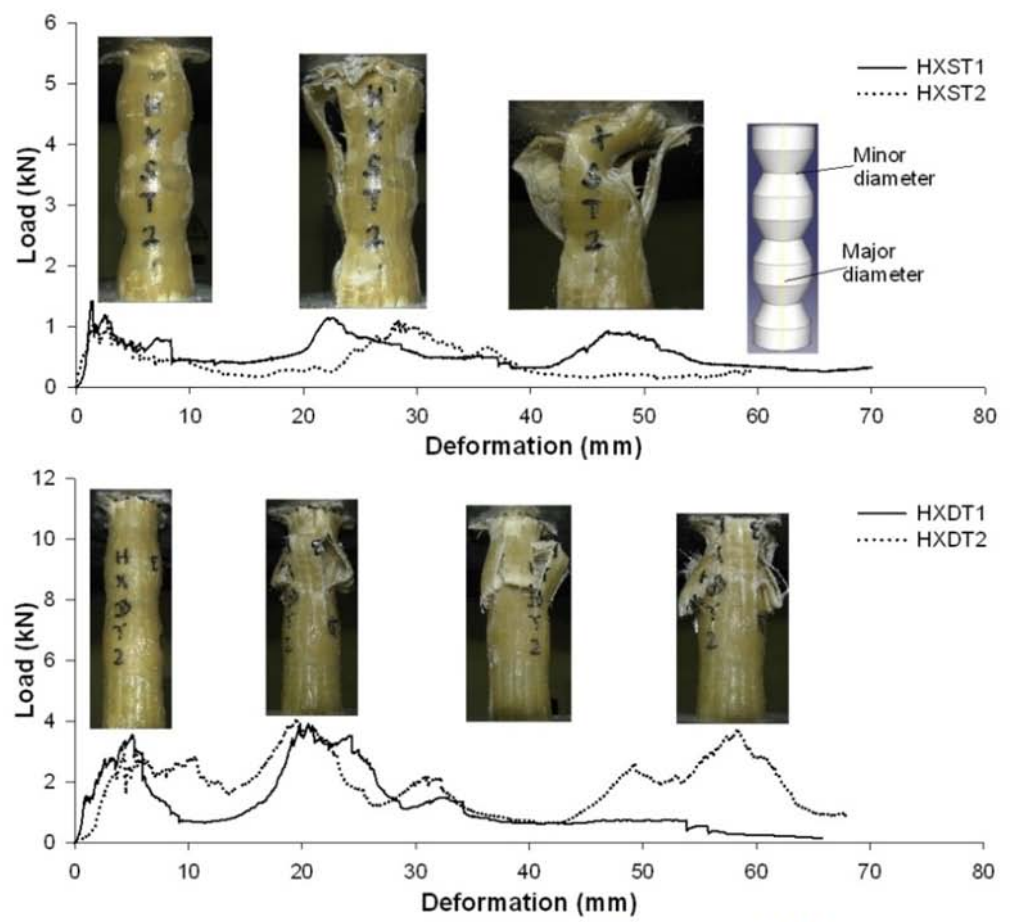

(b) Load - deformation histories (top - HXST1 and HXST2; bottom HXDT1 and HXDT2).

Figure 12: Deformation patterns and the crushing performance of the hourglass type - $\mathrm{X}$ shaped composite tubes. 

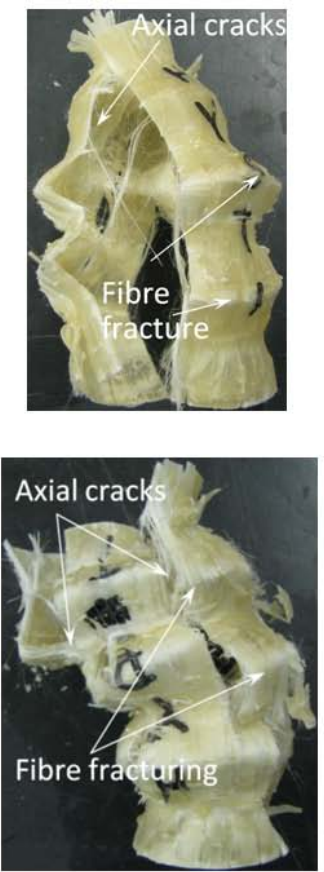

(a) Final deformation patterns (top - HYST1; bottom- HYDT1).
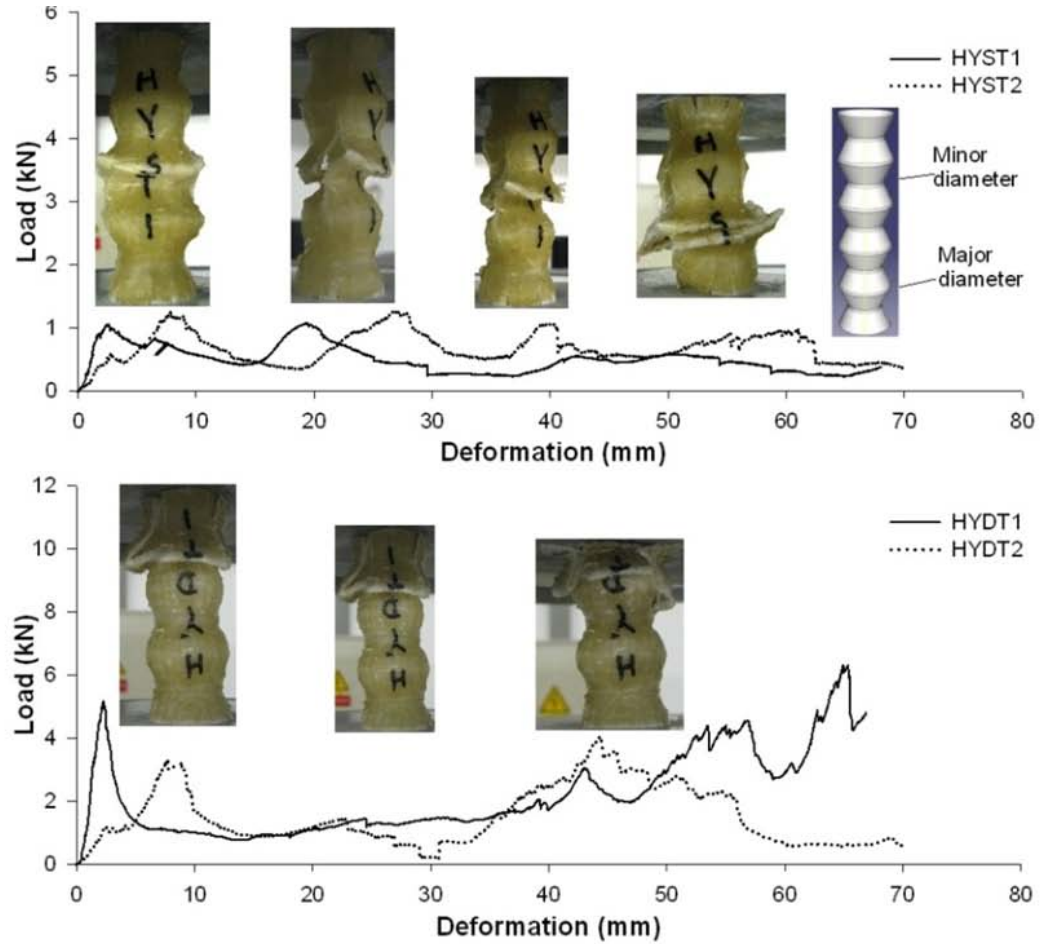

(b) Load - deformation histories (top - HYST1 and HYST2; bottom HYDT1 and HYDT2).

Figure 13: Deformation patterns and the crushing performance of the hourglass type - Y shaped composite tubes.
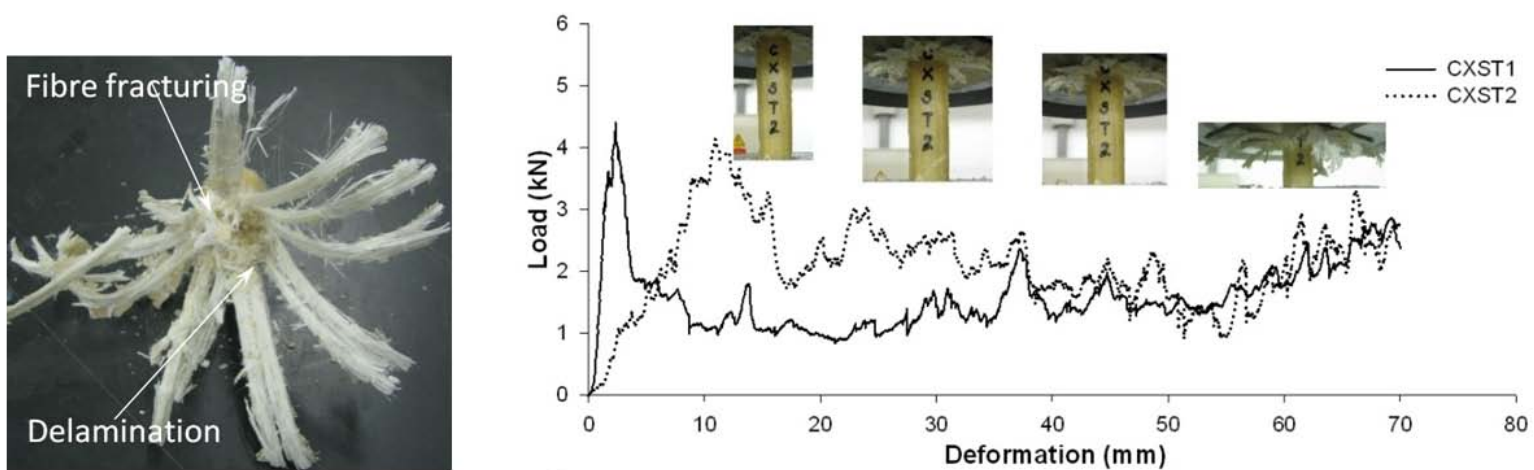

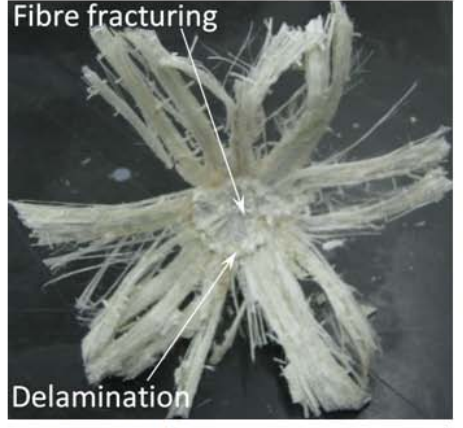

(a) Final deformation patterns (top - CXST1; bottom - CXDT2).

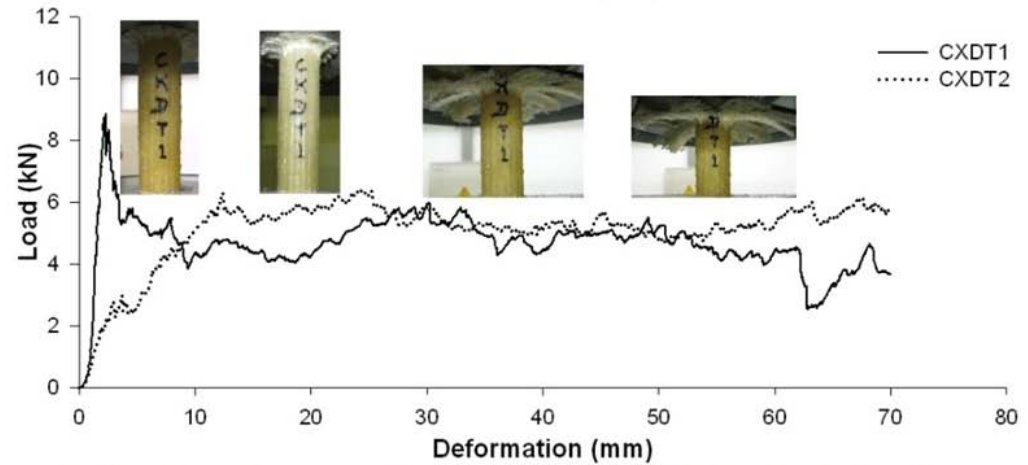

(b) Load - deformation histories (top - CXST1 and CXST2; bottom CXDT1 and CXDT2).

Figure 14: Deformation patterns and the crushing performance of the conical circular type - $X$ shaped composite tubes. 

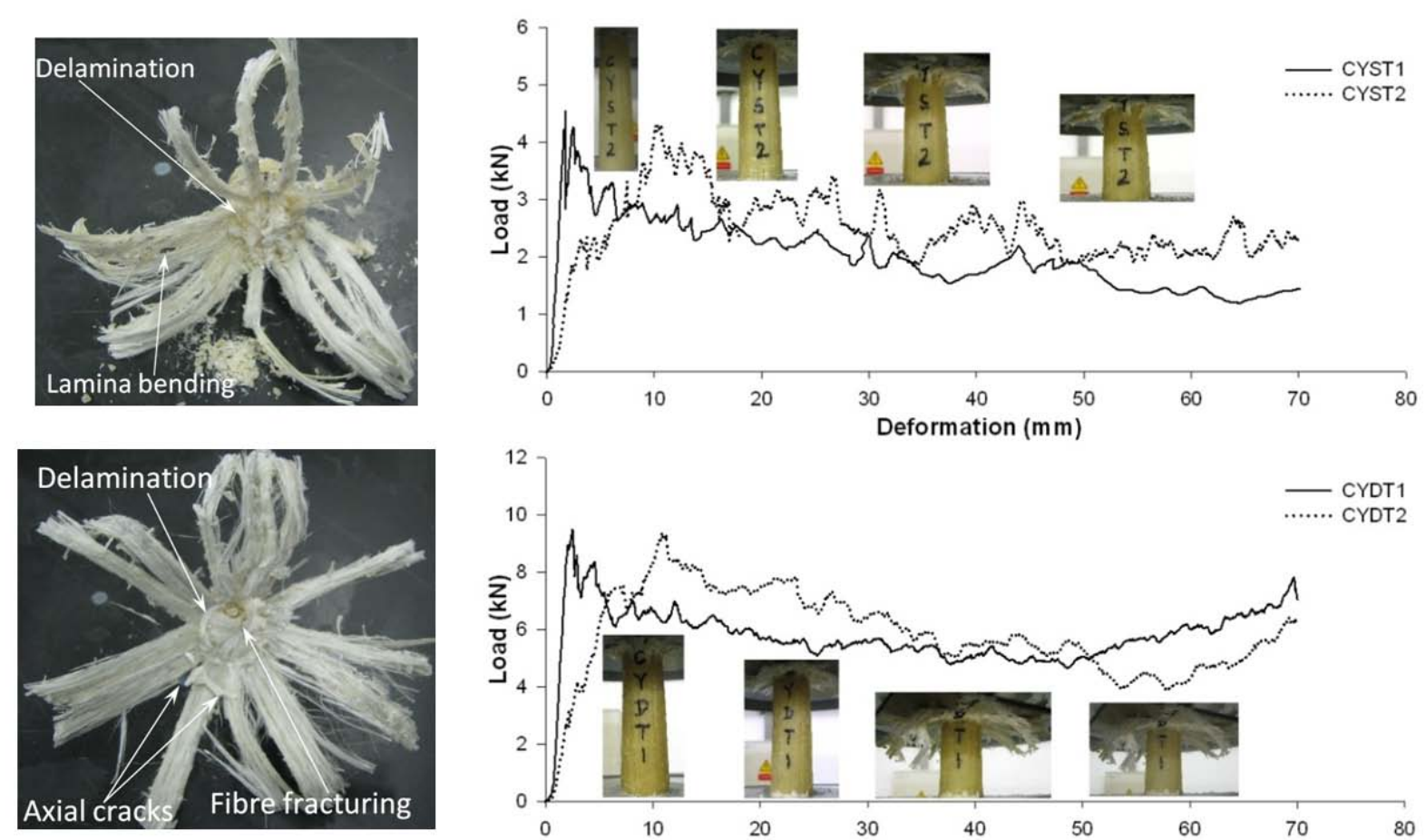

(a) Final deformation patterns (top-CYST1; bottom - CYDT2).

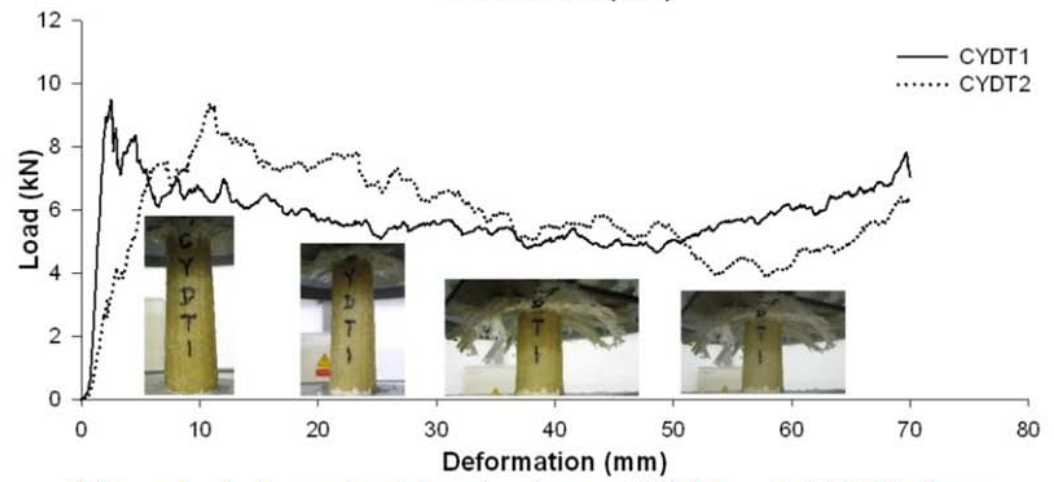

(b) Load - deformation histories (top - CYST1 and CYST2; bottom CYDT1 and CYDT2).

Figure 15: Deformation patterns and the crushing performance of the conical circular type - Y shaped composite tubes.

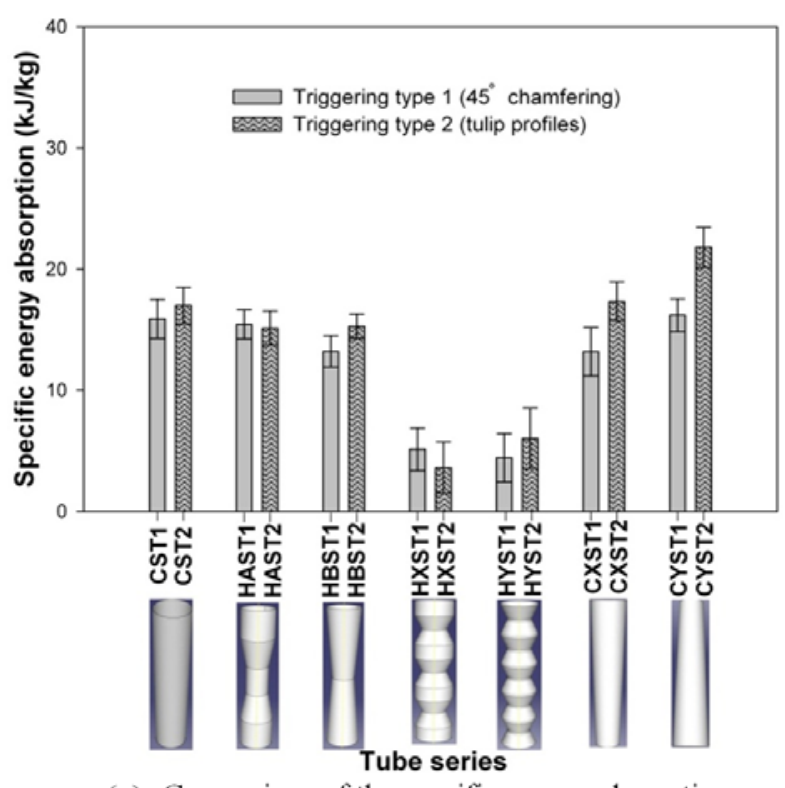

(a) Comparison of the specific energy absorption.

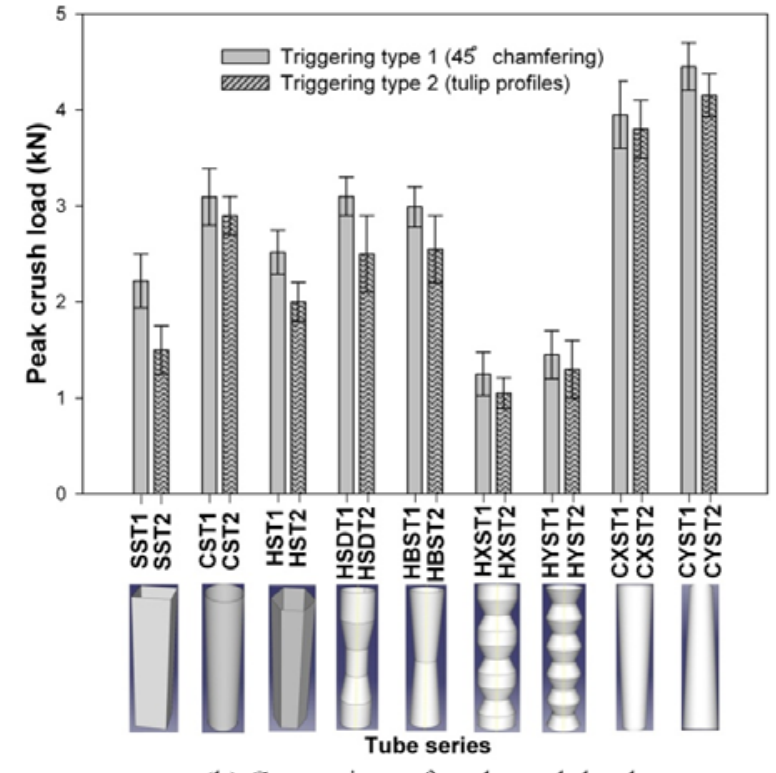

(b) Comparison of peak crush load.

Figure 16: Comparison of the specific energy absorption and peak crush load for $1 \mathrm{~mm}$ thickness composite tube series. 


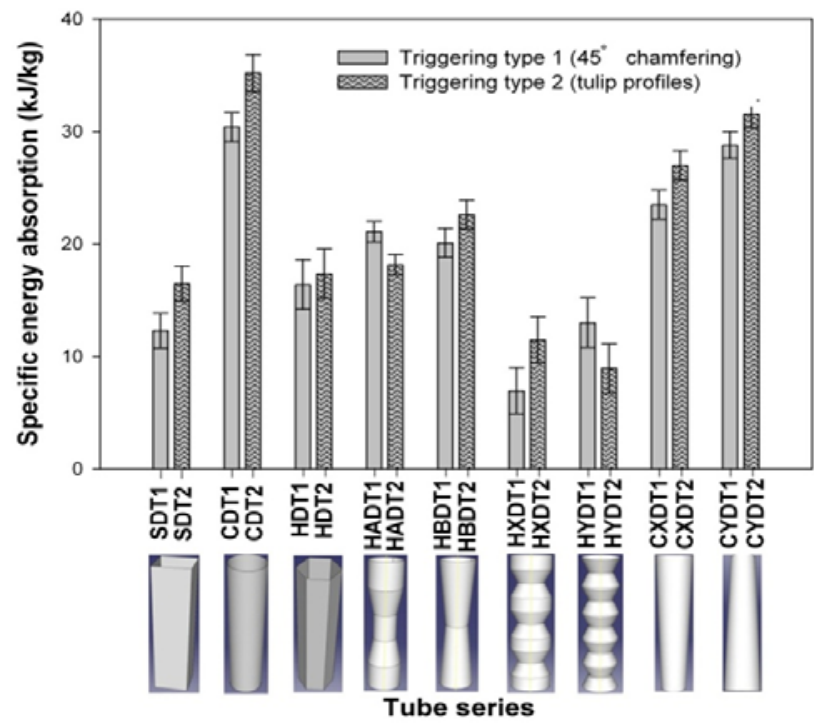

(a) Comparison of specific energy absorption

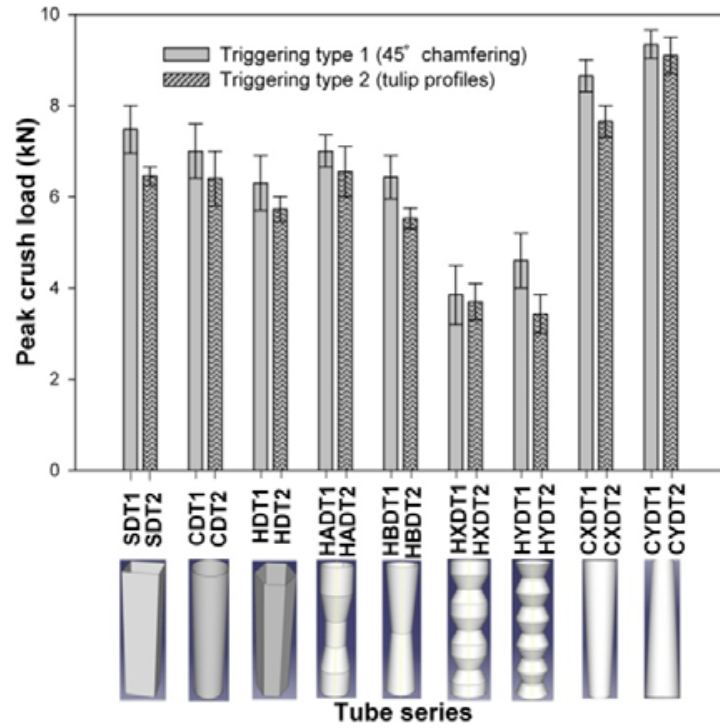

(b) Comparison of peak crush load Figure 17: Comparison of specific energy absorption and peak crush load for $2 \mathrm{~mm}$ thickness composite tube series. 